This item was submitted to Loughborough's Research Repository by the author.

Items in Figshare are protected by copyright, with all rights reserved, unless otherwise indicated.

\title{
The application of discrete event simulation and system dynamics in the logistics and supply chain context
}

PLEASE CITE THE PUBLISHED VERSION

http://dx.doi.org/10.1016/j.dss.2011.11.015

PUBLISHER

(C) Elsevier

VERSION

AM (Accepted Manuscript)

LICENCE

CC BY-NC-ND 4.0

\section{REPOSITORY RECORD}

Tako, Antuela A., and Stewart Robinson. 2019. "The Application of Discrete Event Simulation and System Dynamics in the Logistics and Supply Chain Context”. figshare. https://hdl.handle.net/2134/9500. 
This item was submitted to Loughborough's Institutional Repository (https://dspace.lboro.ac.uk/) by the author and is made available under the following Creative Commons Licence conditions.

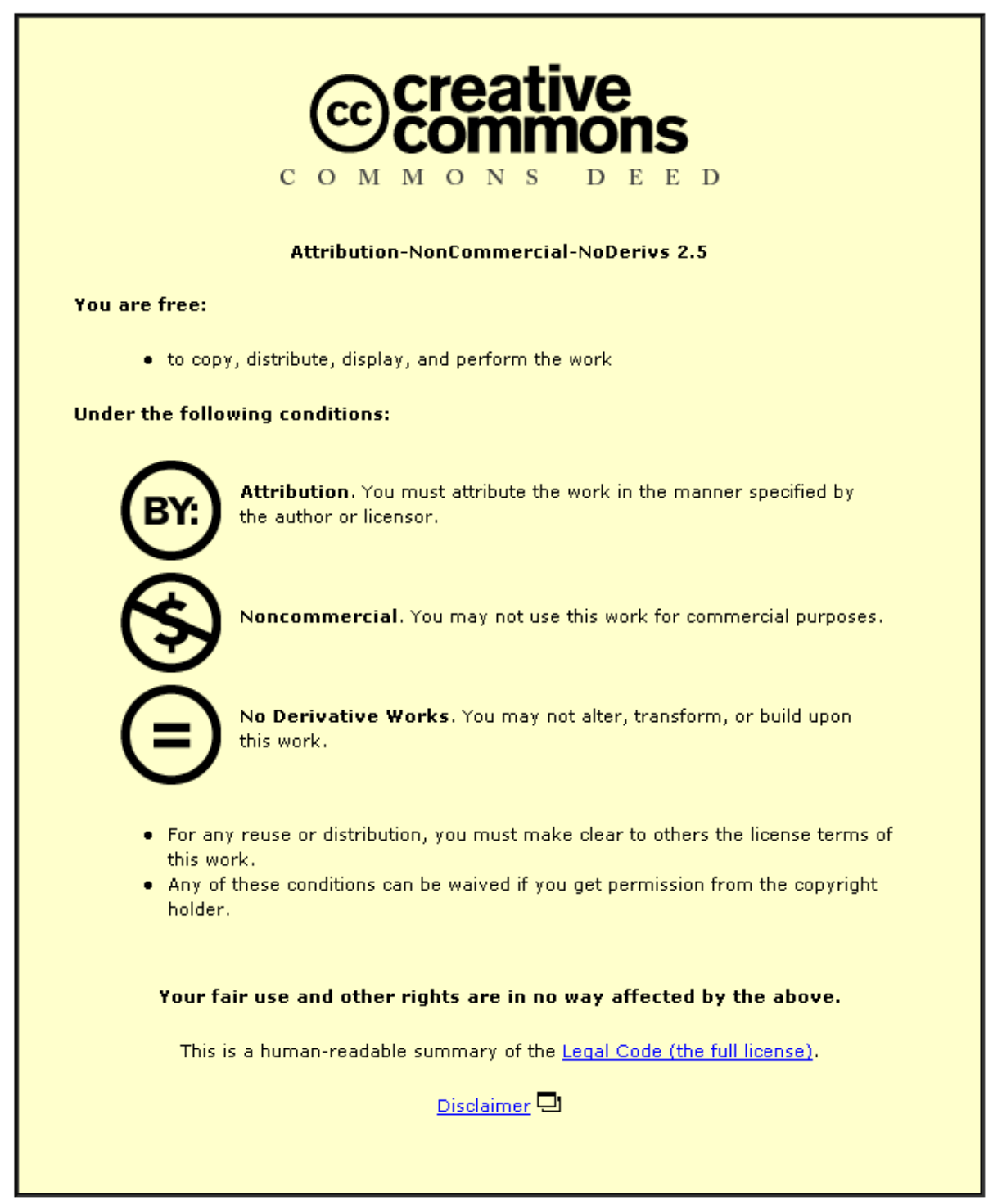

For the full text of this licence, please go to: http://creativecommons.org/licenses/by-nc-nd/2.5/ 


\section{The application of discrete event simulation and system dynamics in the logistics and supply chain context}

Antuela A. Tako* and Stewart Robinson

School of Business and Economics, Loughborough University, Loughborough, LE11 3TU, UK

\section{Author Biographies}

Antuela A. Tako is a Lecturer in Operations Research at the School of Business and Economics, Loughborough University. She holds a PhD in Simulation and an MSc in Management Science and Operational Research from the University of Warwick. She previously worked for a research project that introduces stakeholder participation and facilitation in discrete-event simulation modelling. Her research interests include the comparison of simulation approaches (discrete-event simulation and system dynamics), participative simulation modelling and conceptual modelling.

Stewart Robinson is Professor of Management Science at Loughborough University, School of Business and Economics. Previously employed in simulation consultancy, he supported the use of simulation in companies throughout Europe and the rest of the world. He is author/co-author of five books on simulation. His research focuses on the practice of simulation model development and use. Key areas of interest are conceptual modelling, model validation, output analysis and alternative simulation methods (discrete-event, system dynamics and agent based). He has recently completed a research project that investigated the use of simulation with lean in healthcare. Professor Robinson is co-founder of the Journal of Simulation and Vice President of the United Kingdom Operational Research Society.

\footnotetext{
*E-mail addresses: a.takou@lboro.ac.uk (AA. Tako) and s.l.robinson@lboro.ac.uk (S. Robinson)
} 


\begin{abstract}
Discrete event simulation (DES) and system dynamics (SD) are two modelling approaches widely used as decision support tools in logistics and supply chain management (LSCM). A widely held belief exists that SD is mostly used to model problems at a strategic level, whereas DES is used at an operational/tactical level. This paper explores the application of DES and SD as decision support systems (DSS) for LSCM by looking at the nature and level of issues modelled. Peer reviewed journal papers that use these modelling approaches to study supply chains, published between 1996 and 2006 are reviewed. A total of 127 journal articles are analysed to identify the frequency with which the two simulation approaches are used as modelling tools for DSS in LSCM. Our findings suggest that DES has been used more frequently to model supply chains, with the exception of the bullwhip effect, which is mostly modelled using SD. Based on the most commonly used modelling approach, issues in LSCM are categorised into four groups: the DES domain, the SD domain, the common domain and the less common domain. The study furthermore suggests that in terms of the level of decision making involved, strategic or operational/tactical, there is no difference in the use of either DES or SD. The results of this study inform the existing literature about the use of DES and SD as DSS tools in LSCM.
\end{abstract}

Keywords: logistics and supply chain management; simulation modelling; discrete-event simulation; system dynamics; comparison of methods.

\title{
1. Introduction
}

Discrete-event simulation (DES) and system dynamics (SD) are two widely used modelling tools which underpin decision support systems (DSS) [79, 115, 149, 156]. In the field of logistics and supply chain management (LSCM) simulation-based DSS provide solutions to a wide range of issues at both a strategic, operational and tactical level. Specific examples of the issues that these DSS address are supply chain design and reconfiguration, inventory planning and management, production scheduling and supplier selection [24, 26, 75, 103, 132]. Despite the wide use of DES and SD in LSCM, the exact pattern of their use as DSS for specific LSCM issues is not well understood.

This paper aims to explore the application of DES and SD in LSCM with a view to identifying differences and/or similarities in terms of the nature and level of their use. We define the nature of use in terms of the type of LSCM issues modelled using DES and SD. 
The level of use refers to where on a continuum between strategic and operational/tactical the LSCM issue being addressed lies.

This study explores an important issue in the comparison of modelling methods, that is, the type of problems addressed by different modelling methods. Its contribution is twofold. First, it sheds light on the validity of established views about the differences in the use of DES and SD. Second, it provides a classification of LSCM issues and simulation modelling approach that can serve as supporting evidence in the selection of modelling approach for DSS. Of course, a wider range of criteria need to be considered when choosing between modelling approaches. For instance, Brennan et al [15] provide a taxonomy of models (including DES and SD) for economic evaluation of health technologies. They list a number of criteria that could affect the choice of modelling, including: decision makers’ requirements, system characteristics and system complexity. This paper focuses specifically on one criterion, the type of problems that are being modelled using DES and SD in the LSCM context.

In order to explore the application of DES and SD in LSCM, we undertake a literature review of published papers that use simulation modelling to support decision making in the LSCM context. LSCM is considered a suitable domain for this review due to the fact that both simulation approaches have been extensively used to support decision making activities. Furthermore, decisions made within LSCM involve different levels of the DSS hierarchy: operational, tactical and strategic [83, 132]. The literature search undertaken looks into the LSCM issues modelled using each simulation approach in order to identify the issues most modelled with either or both simulation approaches. This in turn, provides evidence about whether there are differences in the nature and level of LSCM issues modelled by each approach. A search using the Web of Knowledge database was performed to identify journal articles, published in the 11-year period from 1996 to 2006, that undertake simulation modelling in the LSCM context.

The rest of this paper is structured as follows. In the next section, the literature comparing DES and SD and the types of problems modelled is considered. This is then followed by a description of the review approach taken, including the identification of journal articles and the simulation approach adopted, the creation of a schema for classifying the LSCM issues modelled, and the identification of whether these issues lie within the strategic, tactical or operational level of DSS. The results of the literature search are presented in section 4. Finally, section 5 concludes the paper, including suggestions for further work. 


\section{DES and SD: comparison and use}

Here we briefly review literature that provides a comparison of DES and SD as well as the opinions found with regards to the type of problems modelled and level of use (strategic, tactical and operational) of the simulation methods.

\subsection{Comparing DES and SD}

DES and SD developed independently from each other from the late 1950s, with very little communication between the two fields. It is only in recent years that significant interest in comparing the two approaches has emerged. As such, comparison work on the differences and similarities between the two approaches is limited. The existing work largely consists of opinion-based statements which are often influenced by the authors' field of expertise [141]. It has been claimed that DES and SD are quite different modelling approaches, especially in terms of the type of problems modelled [14]. There is a general belief that DES is considered to be more suitable for modelling problems at an operational/tactical level, whereas SD is more suited to modelling problems at a strategic level. However, others claim that the divide between the two modelling approaches might not be so clear-cut. Different aspects of the same problem may be highlighted by each modelling approach [99], but on the other hand, if the problem is similarly represented in both approaches, similar outcomes can be observed from the users' point of view [140].

Simulation models, in both DES and SD, are usually built to understand how systems behave over time and to compare their performance under different conditions [139]. Some technical differences exist between the two modelling approaches related to their underlying principles. For example, DES models systems as a network of queues and activities where state changes occur at discrete points of time, whereas SD models represent a system as a set of stocks and flows where the state changes occur continuously over time [14]. In DES entities (objects, people) are represented individually. Specific attributes are assigned to each entity, which determine what happens to them throughout the simulation. On the other hand, in SD individual entities are not specifically modelled, but instead they are represented as a continuous quantity in a stock. DES models are generally stochastic in nature, where randomness is generated through the use of statistical distributions. SD models are generally deterministic and variables usually represent average values. In DES state changes occur at irregular discrete time steps, while in SD state changes are continuous, approximated by small discrete steps of equal length. For more information about these modelling approaches, interested readers are referred to relevant textbooks [80, 114, 126] and [136]. 
The opinions found in the comparison literature refer mainly to the practice of model development, the modelling philosophy and the use of respective models. We next consider in more detail the opinions with regards to the nature and level of problems modelled using each modelling approach.

\subsection{Opinions on the nature and level of use of DES and SD}

Considering the nature of problems modelled using each simulation technique, the comparison literature states that SD focuses mainly on strategic issues and policy analysis, while DES is generally used to study problems at an operational or tactical level $[77,139$, 143]. Based on the differences between discrete and continuous systems, it is suggested that the choice of one or the other approach depends on the conceptual difference from which one views the problem [123]. The SD approach is considered appropriate when taking a 'distant' perspective (meaning strategic) where events and decisions are seen in the form of patterns of behaviour and system structures [123].

Several papers suggest that DES is not suitable for strategic modelling as it does not normally represent systems at an aggregate level $[9,81,108]$. To cater for this disadvantage, a number of studies $[59,81,116]$ have suggested the use of hybrid simulation approaches combining DES and SD. For example in a study of an integrated manufacturing enterprise system [116], DES was used to model local production decisions for selected parts of the enterprise, while the SD model captured the long term effects of these decisions on the entire enterprise and the interactions between decisions made at different levels of management. The same study points out the factors that make SD suitable for high level strategic modelling, which one could consider as generally accepted claims found in the existing comparison literature, which have not been empirically validated. These factors consist of the following:

- Takes a holistic approach of systems, integrating many subsystems

- Focuses on policies and system structure

- Use of feedback loops to represent the effects of policy decisions

- Represents a dynamic view of the cause and effect relationships among the system elements

- SD has minimal data requirements to build a model. 
In a study of a manufacturing plant, the successful use of the DES approach to investigate the operational aspects of a production-planning facility is reported [54]. The outcome of the DES study was the recommendation of new production sequencing activities. In addition, it emerged that the disruptions in production planning in the manufacturing plant needed to be further considered. In this case, the SD approach was preferred in order to model the softer aspects related to the problem of disruptions. The SD approach was considered to be more useful for modelling the organisational context of the problem and so moved on to extend the already created DES model using SD.

In another study two models of a supply chain were developed, a discrete event and a hybrid discrete-continuous simulation model [81]. Comparing the results of the two models, the discrete event model overestimated the outputs of the inventory levels compared to those of the combined discrete-continuous model, hence resulting in unnecessary inventory. This was due to the difference between the values for elements such as customer orders, information flows and inventory levels, which were defined as continuous in the combined model. The paper recommends the use of hybrid simulation models for supply chains, which were shown to be neither completely discrete nor continuous systems. With regards to the level of problems modelled, the use of analytical models is suggested for modelling at operational levels, DES for modelling at tactical level, while hybrid simulation models for modelling at strategic levels.

On the other hand, various authors have expressed the view that, even though it has not yet been adequately exploited, SD can be successfully used in modelling operational systems. For example, an operational SD model of an earth-moving system was developed for a study of construction management [58]. The SD model was then compared to an equivalent (already existing) DES model. The study suggests that an SD-based operational model can address the operational aspects of the model as accurately and reliably as a DES-based model. The advantages of using SD at an operational level are discussed. These include modelling of feedback effects, managerial actions and soft variables. Furthermore, the potential of using SD modelling in manufacturing systems modelling is suggested in [108]. Considering the inherent characteristics of the two modelling techniques, SD is recommended as a better choice in the intermediate stages of decision making when less detailed models or results are required. Some of the advantages of SD modelling with respect to the requirements of decision making at intermediate stages of evaluation are: the simplicity of the data required, ease of building a simulation model and reduced execution time. Obviously, 
these are statements which represent authors' opinions and have not been empirically verified for their accuracy.

In the LSCM context, DES and SD have been used extensively as decision support tools. However, a systematic and conclusive review of simulation modelling of supply chains does not yet exist. Mula et al. [100] recommend the need for empirical work to compare the use of different modelling approaches in practice, even though they base their study only on a subset of LSCM issues, that of production planning. Different authors provide some preliminary classifications about the use of different modelling approaches, including DES and SD, for DSS in LSCM. Shah [129], for example, provides some examples selected from the literature rather than a comprehensive list of all existing supply chain papers. He concludes that simulation modelling (DES and SD) is mostly used to model issues for supply chain analysis and policy formulation. DES/stochastic models are mainly used to study the detailed operations of a supply chain under uncertainty and/or to evaluate the expected performance measures to a high level of accuracy, whereas SD modelling tends to concentrate on logistics and inventory planning, and not that much on production aspects.

In summary, based on the literature considered in this section, it is obvious that there is a general belief that SD modelling is more suitable for modelling at a strategic level and DES at an operational/tactical level. Some views have been expressed about the suitability of using SD to model problems at an operational level. Ingalls [67], on the other hand, points out that DES can play a significant role in modelling supply chains at a strategic and tactical level. In their study comparing DES and SD, Morecroft and Robinson contemplate that there is not a straightforward distinction between the two approaches, but that it is rather a result of a careful consideration of various criteria: "Perhaps there is both 'strategic DES' and 'operational SD' and it's just a matter of which components you chose for your simulated enterprise” [99]. Meanwhile, others consider the use of combined or hybrid approaches, especially for modelling supply chains. With regards to this point, while the existing views in the literature are largely based on personal opinions and authors' personal experience, this paper uses evidence based on published DES and SD simulation studies in the LSCM literature.

\section{The research approach}

The aim of this study is to explore the use of DES and SD as DSS for LSCM, looking specifically into the nature and level of issues modelled. In order to achieve this we base our analysis on the frequency with which issues in LSCM are modelled using DES and SD. We 
believe that this is appropriate since both simulation approaches have been used extensively in the LSCM context.

The study is based on a review of journal articles that describe the application of DES and SD to LSCM issues. We address the following two research questions:

- Are DES and SD modelling used to model different LSCM issues?

- Is DES used more for operational/tactical problems and SD more for strategic problems?

Based on the previous literature our expectations are that the two approaches will be used to model different aspects of the supply chain, although there will be some overlaps in the issues addressed. We also expect to confirm the view that DES is more operational/tactical and SD more strategic in focus, at least based on their application as described in the extant literature.

The literature review undertaken follows four stages: identification of journal articles and simulation approach adopted, creation of a schema for classifying papers by LSCM issue, distinguishing between strategic and operational/tactical LSCM issues, and classifying papers by the LSCM issues addressed. In performing this analysis we have made no judgement about whether the most appropriate modelling approach was selected, we simply observe which approach is used for which issue. It is almost certainly the case that for at least some of the papers the choice of modelling approach was not optimal. Instead it is likely to have been based on a range of subjective factors such as the modeller's expertise. Since such information is not consistently reported in the papers studied, it is not possible to make judgements about the optimality of the models employed.

Each of the stages followed to undertake this research is now described.

\subsection{Identification of journal articles and simulation approach adopted}

Journal papers that report simulation models relevant to DSS for LSCM were selected based on a keyword search using the Web of Knowledge citation database. This provides a multidisciplinary collection of literature including subjects such as sciences and engineering, social sciences and humanities. The keywords used were 'supply chain', 'simulation', 'discrete-event simulation' and 'system dynamics'. These were combined to include the first keyword ('supply chain') and one of the other keywords mentioned, connected by 'and'. The search included only journal papers published during the 11 year period, between 1996 and 
2006. After removing duplicates, the initial list produced resulted in approximately 400 entries.

The search was limited to journal papers only and no books, conference papers or grey literature were included. As such, all articles included in the review are known to have been subject to full peer review. Given that our aim is to compare modelling work in DES and SD, other simulation approaches such as agent-based modelling and Monte Carlo simulation are not included.

A screening process was carried out to make sure that only papers actually using DES or SD modelling in LSCM were included. In some cases this was identified by reading the abstract, while in other cases this was only revealed in the main text of the paper. There were also cases where the type of modelling approach used was not clear, in which case the authors were directly contacted to enquire. Surprisingly, in many papers, analytical models using heuristics and genetic algorithms, were developed, which were claimed to be analytical ‘simulation' models. A similar observation was also made in [95]. Following this screening process, the list of papers was reduced to 127 . For each of these 127 articles the simulation approach adopted was identified as DES, SD or hybrid (i.e. a mixed DES/SD approach). A full list of the 127 articles is provided in Appendix 1.

\subsection{Creation of a schema for classifying papers by LSCM issue}

The next stage was to devise a schema for classifying the papers into the LSCM issues that each paper addressed. Existing classifications of LSCM issues were initially consulted. Supply chain management is a vast subject, covering a wide variety of topics [104]. A thorough classification of the topics covered in the supply chain literature has not been found. For instance, Chopra and Meindl [24] suggest three high-level categories of topics based on the type of decisions made: design, planning and operation.

A few studies that undertake a literature review of simulation modelling of supply chains have been found, but these are far from systematic. For example, a literature review of the state of the art of supply chain modelling undertaken in OR/MS and engineering is provided by Shah [129]. He categorises LSCM issues into three main areas: network design, analysis and policy formulation, and supply chain planning and scheduling. For each area he provides an overview of the key modelling work undertaken over time. In his review, Shah provides an account of key literature in supply chain modelling work, not necessarily limited to simulation modelling, but does not cover the breadth of papers published. 
Other reviews include studies that use only one type of modelling approach. For example, some studies [6, 106] consider mainly SD models, whereas others [22] draw their conclusions based on studies using analytical and DES modelling only. Furthermore, the classification categories found in the literature do not cover the breadth of LSCM issues modelled. This is illustrated in Table 1, where the classifications displayed include only a limited range of LSCM issues.

Table 1: Classification categories of LSCM topics identified

\begin{tabular}{|c|c|c|c|c|}
\hline $\begin{array}{l}\text { Angerhofer \& } \\
\text { Angelides [19] }\end{array}$ & $\begin{array}{l}\text { Otto and } \\
\text { Kotzab [20] }\end{array}$ & $\begin{array}{l}\text { Chan and Chan } \\
\text { [21] }\end{array}$ & Shah [15] & Our categories \\
\hline $\begin{array}{l}\text { Supply chain } \\
\text { design }\end{array}$ & $\begin{array}{l}\text { Uncoordinated } \\
\text { ordering } \\
\text { behaviour }\end{array}$ & $\begin{array}{l}\text { Product \& process } \\
\text { design }\end{array}$ & $\begin{array}{l}\text { Supply chain } \\
\text { design }\end{array}$ & $\begin{array}{l}\text { Supply chain } \\
\text { structure }\end{array}$ \\
\hline $\begin{array}{l}\text { Supply chain re- } \\
\text { engineering }\end{array}$ & $\begin{array}{l}\text { Distortion of } \\
\text { demand pattern }\end{array}$ & Vendor selection & $\begin{array}{l}\text { Supply chain } \\
\text { analysis \& } \\
\text { policy } \\
\text { formulation }\end{array}$ & Process redesign \\
\hline $\begin{array}{l}\text { Demand } \\
\text { amplification }\end{array}$ & $\begin{array}{l}\text { Poor inventory } \\
\text { visibility }\end{array}$ & $\begin{array}{l}\text { Information } \\
\text { sharing/coordination } \\
\text { mechanisms }\end{array}$ & $\begin{array}{l}\text { Supply chain } \\
\text { planning \& } \\
\text { scheduling }\end{array}$ & Supplier selection \\
\hline \multirow[t]{14}{*}{$\begin{array}{l}\text { Inventory } \\
\text { management }\end{array}$} & $\begin{array}{l}\text { Uncoordinated } \\
\text { demand planning } \\
\text { and forecasting }\end{array}$ & $\begin{array}{l}\text { Inventory } \\
\text { management \& } \\
\text { replenishment } \\
\text { process }\end{array}$ & & $\begin{array}{l}\text { Facilities/capacity } \\
\text { planning/utilisation }\end{array}$ \\
\hline & $\begin{array}{l}\text { Uncoordinated } \\
\text { manufacturing } \\
\text { control }\end{array}$ & $\begin{array}{l}\text { Production } \\
\text { distribution/ } \\
\text { planning and } \\
\text { scheduling }\end{array}$ & & $\begin{array}{l}\text { Replenishment } \\
\text { control policies }\end{array}$ \\
\hline & & & & Bullwhip effect \\
\hline & & & & Information sharing \\
\hline & & & & $\begin{array}{l}\text { Supply chain } \\
\text { integration }\end{array}$ \\
\hline & & & & $\begin{array}{l}\text { Supply chain } \\
\text { optimisation }\end{array}$ \\
\hline & & & & Cost reduction \\
\hline & & & & System performance \\
\hline & & & & $\begin{array}{l}\text { Inventory planning/ } \\
\text { management }\end{array}$ \\
\hline & & & & $\begin{array}{l}\text { Planning \& } \\
\text { Forecasting demand }\end{array}$ \\
\hline & & & & $\begin{array}{l}\text { Production planning } \\
\text { \& scheduling }\end{array}$ \\
\hline & & & & $\begin{array}{l}\text { Distribution \& } \\
\text { transportation } \\
\text { planning }\end{array}$ \\
\hline & & & & Dispatching rules \\
\hline & & & & Reverse logistics \\
\hline
\end{tabular}


Based on the existing classifications found in the literature, a customised list of issues was developed, which apart from grouping the LSCM issues found in Table 1, also included additional issues that were identified from the 127 papers that form the basis of this study. The final list of issues is shown in Figure 1. A more full explanation of each of these LSCM issues is provided in Appendix 2.

\subsection{Distinguishing between strategic and operational/tactical LSCM issues}

Having identified a set of LSCM issues reflecting decisions taken within the supply chain, these were further classified into strategic, tactical and operational issues. Decisions in supply chains can be categorised into the three groups depending on the frequency with which a decision is taken and the time frame during which it makes an impact [24, 83]. Strategic decisions normally deal with company-wide problems involving a time span of between 2 and 5 years. These consist mainly of issues such as supply chain configuration and resource allocation. Tactical decisions involve mid-term activities, that is, over a time period of one month to a year, and involve issues related to supply chain planning. Operational decisions normally involve short-term decisions related to day-to-day activities. The goal of these decisions is to handle incoming customer orders in the best possible way, given the already set supply chain design and planning policies. At the operational level the main problems pursued are lot sizes, replenishment orders, and service levels [51].

Attempting to classify a LSCM issue as being strategic, tactical or operational is not straight forward because it is not always possible to be precise about the nature of the decision and in many cases a simulation study might be addressing overlapping decision levels. For the purposes of this review we ranked the list of issues in Figure 1 between the two extremes of strategic and operational/tactical. The devised ranking is shown on the left side of Figure 1. 


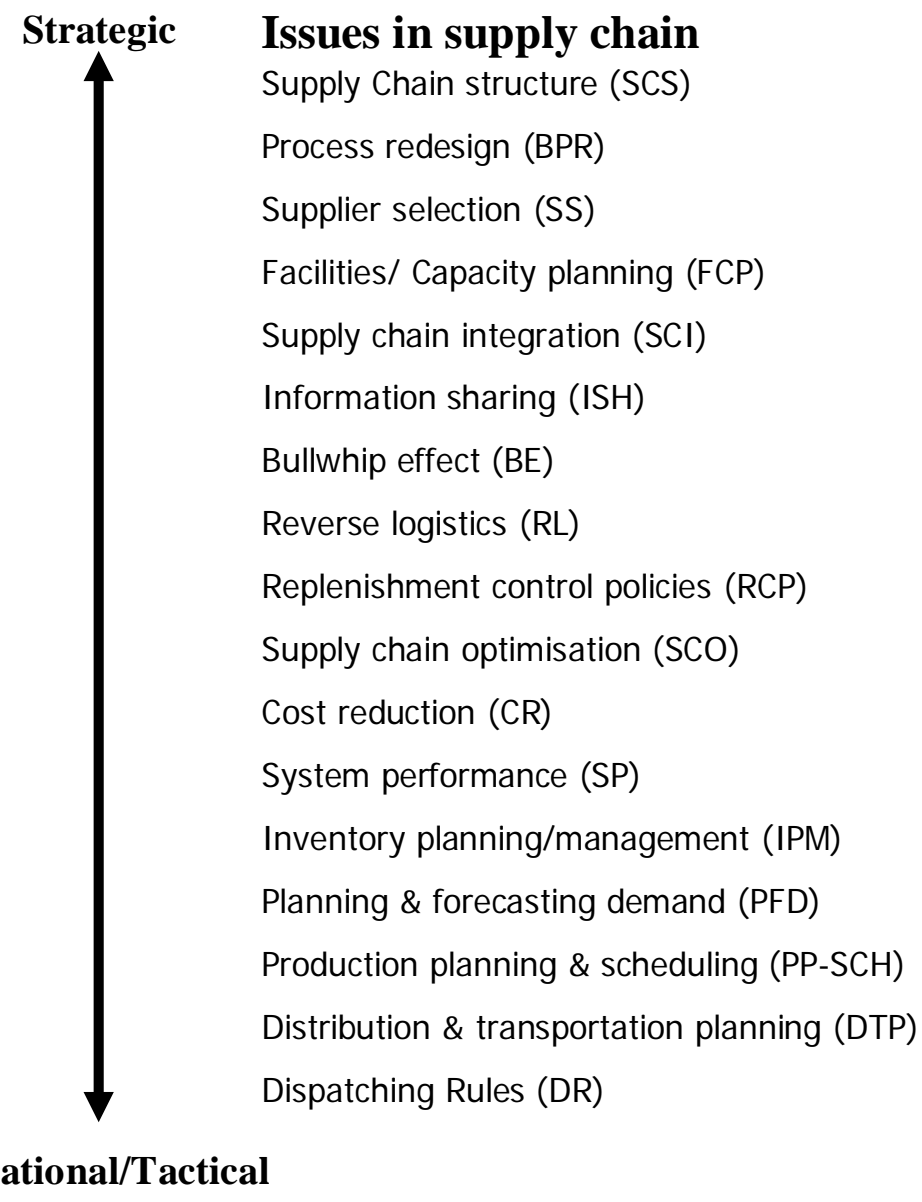

\section{Figure 1: Ordering of LSCM issues into strategic and operational/tactical}

Decision support in LSCM is broadly categorised into strategic, tactical or operational [24, 83, 132], but a detailed distinction of issues has not been found in the literature. Our ranking is largely based on Shah's ordering of the issues. Where we have added further LSCM issues, these have been placed in the ranking based on our interpretation of the issue's strategic or operational/tactical focus in the papers from which the issue was identified. Operational and tactical issues are not specifically separated, since it is difficult to distinguish between the two at the coarse level of an issue descriptor. However, we would expect issues further up the ranking to be more tactical in nature.

Our classification of issues focuses mainly on papers that use simulation, either DES or SD, modelling decisions relevant to DSS in LSCM. Difficulties were encountered in identifying the LSCM issues modelled in the papers reviewed. There is no consistency in the terms used between papers. For example, production planning and management is in some cases referred to as manufacturing policies or production control policies; supply chain instability is often used in place of the bullwhip effect. Hence, the classification of LSCM issues was made based on the authors' judgement and the information provided in the main text of each article. 
Furthermore, for the classification of LSCM issues into strategic, operational/tactical a readily available classification was not available. Shah’s [129] basic guide was used, incorporating the authors' own interpretation, taking into account the time-frame of the decisions involved.

\subsection{Classifying papers by the LSCM issues addressed}

Finally, the 127 journal papers that were selected were further screened, either by reading the abstract or the full text if it was required, with a view to identifying the LSCM issues modelled. In most cases the models described in the papers addressed more than one LSCM issue, resulting in the classification showing papers being associated with more than one issue. The full classification is provided in Appendix 1. The results from analysing this classification are now presented.

\section{Results}

The classification of papers was analysed in order to address the questions of whether DES and SD are used to model different LSCM issues, and to determine whether DES is used more for operational/tactical issues while SD is used more for strategic issues. With respect to this, results are presented from three perspectives: the frequency of use of DES and SD in the LSCM context, the frequency with which LSCM issues are addressed by the two simulation approaches, and the focus of DES and SD on the strategic and operational/tactical levels.

\subsection{The frequency of use of DES and SD in the LSCM context}

Out of the 127 papers, 86 (68\%) used the DES approach, 38 (30\%) the SD approach, while just 3 (2\%) papers used hybrid DES and SD modelling. DES modelling activity is more than double that of SD, suggesting that DES is the most frequently applied simulation approach in the LSCM context. The smaller number of SD papers in supply chain modelling found from this survey could be due to "a period of limited SD modelling activity experienced in the 90s, to resurface back in the late 90s” [145]. After this “slack period”, SD applications in LSCM have significantly increased and so has the number of LSCM issues modelled [6].

In order to investigate these claims, we next consider the trend of DES and SD modelling activity to support decision making in the LSCM context throughout the review period. Figure 2 presents a frequency-of-use timeline for the 124 DES and SD only LSCM papers published in the period between 1996 and 2006. The 3 papers using hybrid modelling are 
omitted from Figure 2 due to its low frequency of use. The graph shows that there was limited supply chain modelling activity using DES in the first five years of the review period, after which there has been a steady growth in the number of DES papers (2001-2006). However, a similar level of growth is not observed for the SD papers. Albeit, an increase in SD applications in the LSCM context in the late 90s has been claimed [6, 145], fewer SD applications have been found compared to DES applications for the same time period. From 2001 onwards DES applications outnumber SD applications. Figure 2 also shows a greater level of growth in the use of DES applications over SD applications for supply chain modelling.

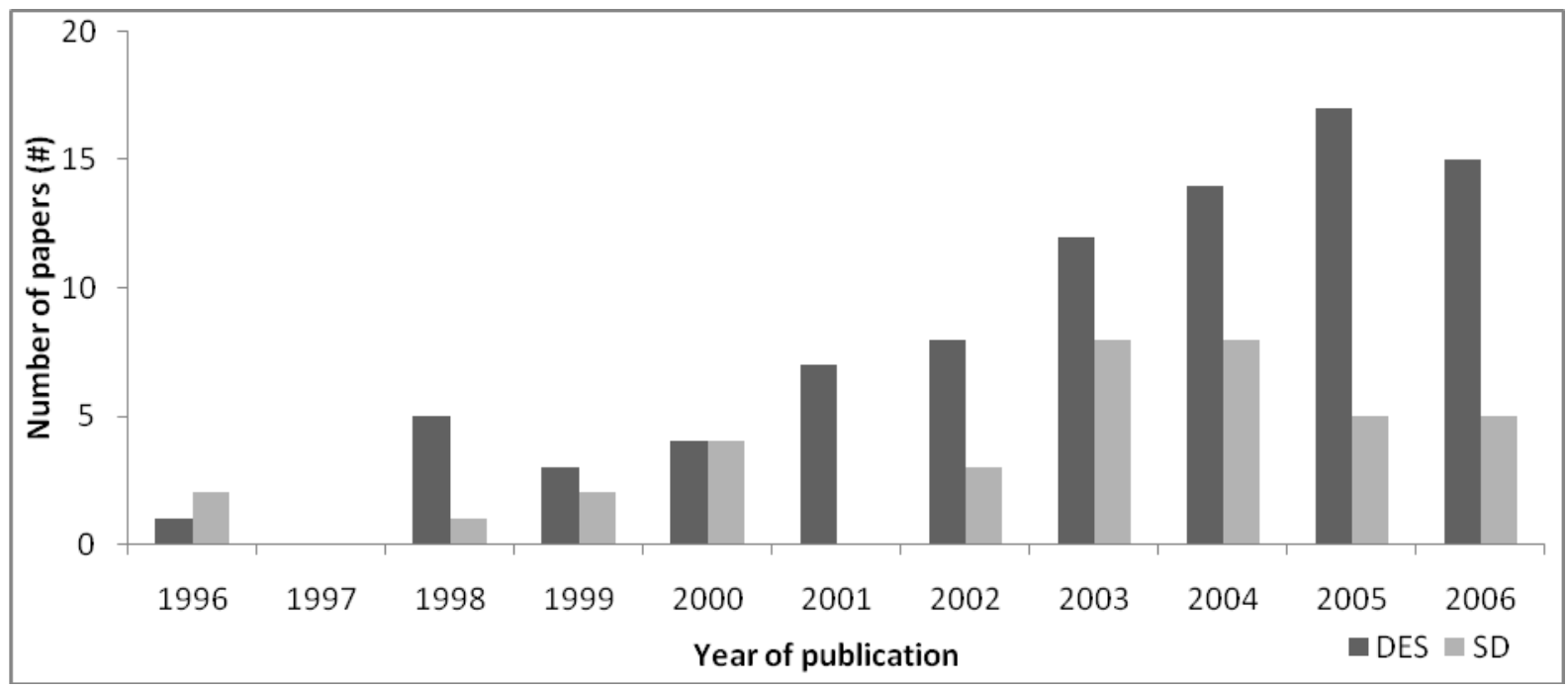

Figure 2: Historical emergence of DES and SD applications in the LSCM context in the period 1996-2006.

\subsection{DES and SD modelling by LSCM issue studied: percentage and frequency of use}

Table 2 shows the extent to which each LSCM issue presented in Figure 1 is addressed by each modelling approach in the papers that form this review. The column for each modelling approach (DES, SD and hybrid-DES/SD) presents the number of papers (\#) that address each LSCM issue. The percentage use by modelling approach (\%) is calculated as the proportion of the number of papers on that specific LSCM issue over the total number of papers identified for that modelling approach (the last row in Table 2). It should be noted that the totals in the last row are higher than the total number of papers reviewed for each approach due to the fact that most papers describe the modelling of more than one LSCM issue. 
Table 2: The extent to which LSCM issues are addressed by each modelling approach; number of papers (\#) and percentage use by modelling approach (\%)

\begin{tabular}{|c|c|c|c|c|c|c|c|}
\hline & \multirow{2}{*}{ LSCM issues ranked } & \multicolumn{2}{|c|}{ DES } & \multicolumn{2}{|c|}{ SD } & \multicolumn{2}{|c|}{ HYB } \\
\hline & & \# & $\%$ & \# & $\%$ & \# & $\%$ \\
\hline \multirow{12}{*}{ 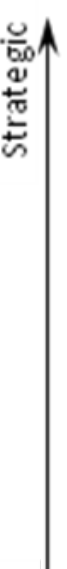 } & Supply Chain structure (SCS) & 16 & $6 \%$ & 2 & $2 \%$ & 1 & $10 \%$ \\
\hline & Process redesign (BPR) & 5 & $2 \%$ & 3 & $3 \%$ & 1 & $10 \%$ \\
\hline & Supplier selection (SS) & 3 & $1 \%$ & 2 & $2 \%$ & 0 & $0 \%$ \\
\hline & Facilities/ Capacity planning (FCP) & 5 & $2 \%$ & 3 & $3 \%$ & 1 & $10 \%$ \\
\hline & Supply chain integration ( $\mathrm{SCl}$ ) & 21 & $8 \%$ & 8 & $8 \%$ & 1 & $10 \%$ \\
\hline & Information sharing (ISH) & 14 & $5 \%$ & 10 & $10 \%$ & 0 & $0 \%$ \\
\hline & Bullwhip effect (BE) & 5 & $2 \%$ & 18 & $18 \%$ & 0 & $0 \%$ \\
\hline & Reverse logistics (RL) & 4 & $2 \%$ & 3 & $3 \%$ & 0 & $0 \%$ \\
\hline & Replenishment control policies (RCP) & 22 & $8 \%$ & 2 & $2 \%$ & 1 & $10 \%$ \\
\hline & Supply chain optimisation (SCO) & 21 & $8 \%$ & 3 & $3 \%$ & 0 & $0 \%$ \\
\hline & Cost reduction (CR) & 10 & $4 \%$ & 2 & $2 \%$ & 0 & $0 \%$ \\
\hline & System performance (SP) & 28 & $11 \%$ & 8 & $8 \%$ & 1 & $10 \%$ \\
\hline \multirow{5}{*}{$\underset{\pi}{\mathbb{\pi}}$} & Inventory planning/management (IPM) & 47 & $18 \%$ & 18 & $18 \%$ & 1 & $10 \%$ \\
\hline & Planning \& forecasting demand (PFD) & 19 & $7 \%$ & 8 & $8 \%$ & 0 & $0 \%$ \\
\hline & Production planning \& scheduling (PP-SCH) & 27 & $10 \%$ & 9 & $9 \%$ & 3 & $30 \%$ \\
\hline & Distribution \& transportation planning (DTP) & 14 & $5 \%$ & 1 & $1 \%$ & 0 & $0 \%$ \\
\hline & Dispatching Rules (DR) & 4 & $2 \%$ & 0 & $0 \%$ & 0 & $0 \%$ \\
\hline$\downarrow$ & Total & 265 & $100 \%$ & 100 & $100 \%$ & 10 & $100 \%$ \\
\hline
\end{tabular}

Percentage use by LSCM issue

Based on the percentages displayed in Table 2 we can identify the issues in LSCM that have been most frequently modelled with each simulation approach. An issue is considered to be frequently modelled if the percentage use for a simulation approach is $10 \%$ or more (shaded cells in Table 2). The issues most often modelled using DES are system performance, inventory planning/management, production planning \& scheduling and system performance. The SD approach is most often used to model issues regarding information sharing, bullwhip effect and inventory planning/management. Hence, inventory planning/management is modelled to a high extent within both simulation approaches, albeit that DES is used much more frequently than SD for this issue based on the count of papers addressing this issue (48 compared to 18 respectively). Hybrid DES/SD is used predominantly for modelling of production planning \& scheduling issues. However, the number of papers found using hybrid modelling is so limited that we cannot make any definitive observations.

Further analysis allows us to identify which percentage use values are significantly different between DES and SD modelling. This shows us which issues DES and SD modellers focus 
on proportionately more in their modelling work. Table 3 shows the results from z-tests for comparing proportions. For each LSCM issue 95\% confidence intervals are calculated in order to test for differences in the percentage use between DES and SD.

Table 3: Confidence intervals of the differences in the percentage use of DES and SD for each LSCM issue (issues with significant differences are highlighted)

\begin{tabular}{|c|c|c|c|c|}
\hline $\begin{array}{l}\text { LSCM issues ranked } \\
\text { (strategic to operational/tactical) }\end{array}$ & $\begin{array}{l}\text { Difference } \\
\text { (DES-SD) }\end{array}$ & $\begin{array}{l}\text { Lower } \\
\text { limit }\end{array}$ & $\begin{array}{l}\text { Upper } \\
\text { limit }\end{array}$ & $\begin{array}{l}\text { Percentage use } \\
\text { (2-sided z-test) }\end{array}$ \\
\hline Supply Chain structure (SCS) & $4 \%$ & $0.1 \%$ & $8 \%$ & DES is higher \\
\hline Process redesign (BPR) & $-1 \%$ & $-4.8 \%$ & $3 \%$ & Similar \\
\hline Supplier selection (SS) & $-1 \%$ & $-3.9 \%$ & $2 \%$ & Similar \\
\hline Facilities/ Capacity planning (FCP) & $-1 \%$ & $-4.8 \%$ & $3 \%$ & Similar \\
\hline Supply chain integration (SCI) & $0 \%$ & $-6.3 \%$ & $6 \%$ & Similar \\
\hline Information sharing (ISH) & $-5 \%$ & $-11.2 \%$ & $2 \%$ & Similar \\
\hline Bullwhip effect (BE) & $-16 \%$ & $-23.8 \%$ & $-8 \%$ & SD is higher \\
\hline Reverse logistics (RL) & $-1 \%$ & $-5.1 \%$ & $2 \%$ & Similar \\
\hline Replenishment control policies (RCP) & $6 \%$ & $2.0 \%$ & $11 \%$ & DES is higher \\
\hline Supply chain optimisation (SCO) & $5 \%$ & $0.3 \%$ & $10 \%$ & DES is higher \\
\hline Cost reduction (CR) & $2 \%$ & $-1.8 \%$ & $5 \%$ & Similar \\
\hline System performance (SP) & $3 \%$ & $-3.9 \%$ & $9 \%$ & Similar \\
\hline Inventory planning/management (IPM) & $0 \%$ & $-9.1 \%$ & $9 \%$ & Similar \\
\hline Planning \& forecasting demand (PFD) & $-1 \%$ & $-7.0 \%$ & $5 \%$ & Similar \\
\hline Production planning \& scheduling (PP-SCH) & $1 \%$ & $-5.5 \%$ & $8 \%$ & Similar \\
\hline Distribution \& transportation planning (DTP) & $4 \%$ & $1.0 \%$ & $8 \%$ & DES is higher \\
\hline Dispatching Rules (DR) & $2 \%$ & $0.04 \%$ & $3 \%$ & DES is higher \\
\hline
\end{tabular}

Significant differences in the proportion of use are found for 6 out of the 17 LSCM issues in Table 3. There is however the probability of conducting a type I error, that is, that any of the 6 issues identified as different from the z-tests may not be different in reality. This is a result of undertaking 17 independent tests, which compare the difference in proportions using multiple confidence intervals. However, due to the high number of categories, relevant tests that can control the type I error (such as Bonferroni) were not considered appropriate because it results in a very small p-value for each independent test.

Based on the differences identified in Table 3, the SD approach has a significantly higher percentage use on the bullwhip effect compared to the DES approach. The DES approach has significantly higher percentage uses for the following LSCM issues: supply chain structure, replenishment control policies, supply chain optimisation, distribution \& transportation planning and dispatching rules. A 1-sided test of the comparison of proportions, which investigates the sign of the differences identified, confirms all 6 differences identified as significant at a $95 \%$ level. 
The frequency with which DES and SD are used for each LSCM issue is shown in the columns labelled \# in Table 2. This shows the number of papers that address each issue.

Figure 3 provides a 100\% stacked column chart for these data, normalised as a proportion of the total papers addressing each LSCM issue. The absolute number of times DES and SD is used for each LSCM issue is also displayed on the relevant part of each bar.

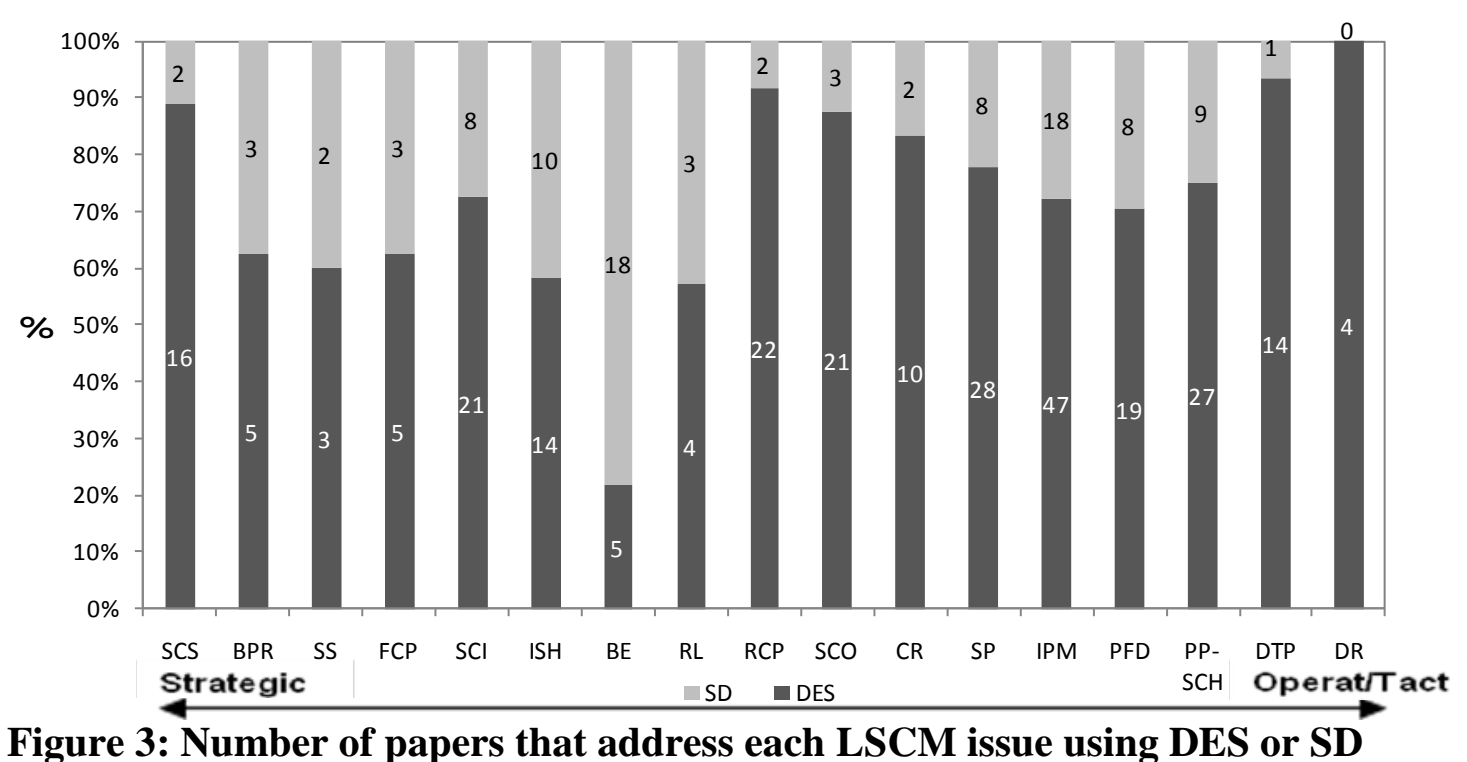

A similar z-test is undertaken to compare the relative difference in the proportion of DES and SD applications for each LSCM issue. Table 4 shows the results from z-tests for comparing proportions. For each LSCM issue 95\% confidence intervals are calculated in order to test for the relative differences in the percentage use between DES and SD. Significant differences in the proportion of use are found for 12 out of the 17 LSCM issues in Table 4. It is found that DES has a relatively higher frequency of use for a number of LSCM issues: supply chain structure, supply chain integration, replenishment control policies, supply chain optimisation, cost reduction, system performance, inventory planning \& management, planning and forecasting demand, production planning \& scheduling, distribution and transportation planning, and dispatching rules. The issue of dispatching rules is exclusively modelled using DES modelling, whereas no issues have been modelled using exclusively the SD approach. The bullwhip effect has been modelled relatively more using the SD approach. It is interesting to notice that this test reveals that inventory planning \& management, which seems to be a highly modelled topic in both DES and SD modelling approaches, is modelled relatively more using the DES approach. 
Table 4: Confidence intervals of the differences in the percentage relative use of DES and SD for each LSCM issue (issues with significant differences are highlighted)

\begin{tabular}{|c|c|c|c|c|}
\hline $\begin{array}{l}\text { LSCM issues ranked (strategic to } \\
\text { tactical/operational) }\end{array}$ & $\begin{array}{l}\text { Relative } \\
\text { Difference } \\
\text { (DES-SD) }\end{array}$ & $\begin{array}{l}\text { Lower } \\
\text { limit }\end{array}$ & $\begin{array}{l}\text { Upper } \\
\text { limit }\end{array}$ & $\begin{array}{l}\text { Relative } \\
\text { Percentage } \\
\text { use (2-sided z- } \\
\text { test) }\end{array}$ \\
\hline Supply Chain structure (SCS) & $78 \%$ & $31.6 \%$ & $124 \%$ & DES is higher \\
\hline Process redesign (BPR) & $25 \%$ & $-44.3 \%$ & $94 \%$ & Similar \\
\hline Supplier selection (SS) & $20 \%$ & $-67.7 \%$ & $108 \%$ & Similar \\
\hline Facilities/ Capacity planning (FCP) & $25 \%$ & $-44.3 \%$ & $94 \%$ & Similar \\
\hline Supply chain integration (SCI) & $45 \%$ & $8.4 \%$ & $81 \%$ & DES is higher \\
\hline Information sharing (ISH) & $17 \%$ & $-23.3 \%$ & $57 \%$ & Similar \\
\hline Bullwhip effect (BE) & $-57 \%$ & $-97.4 \%$ & $-16 \%$ & SD is higher \\
\hline Reverse logistics (RL) & $14 \%$ & $-59.8 \%$ & $88 \%$ & Similar \\
\hline Replenishment control policies (RCP) & $83 \%$ & $43.3 \%$ & $123 \%$ & DES is Higher \\
\hline Supply chain optimisation (SCO) & $75 \%$ & $35.0 \%$ & $115 \%$ & DES is higher \\
\hline Cost reduction (CR) & $67 \%$ & $10.1 \%$ & $123 \%$ & DES is higher \\
\hline System performance (SP) & $56 \%$ & $22.9 \%$ & $88 \%$ & DES is higher \\
\hline Inventory planning/management (IPM) & $45 \%$ & $20.3 \%$ & $69 \%$ & DES is higher \\
\hline Planning \& forecasting demand (PFD) & $41 \%$ & $3.0 \%$ & $78 \%$ & DES is higher \\
\hline Production planning \& scheduling (PP-SCH) & $50 \%$ & $17.3 \%$ & $83 \%$ & DES is higher \\
\hline Distribution \& transportation planning (DTP) & $87 \%$ & $36.1 \%$ & $137 \%$ & DES is higher \\
\hline Dispatching Rules (DR) & $100 \%$ & $\mathrm{n} / \mathrm{a}$ & $\mathrm{n} / \mathrm{a}$ & DES is higher \\
\hline
\end{tabular}

For the LSCM issues process redesign, supplier selection, facilities/capacity planning, information sharing and reverse logistics insignificant differences have been found from the z-tests of proportions. This implies that these LSCM issues have been modelled to a fairly similar extent using either the DES or the SD approach.

\subsection{The focus of DES and SD on the strategic and operational/tactical levels}

In order to identify whether DES is used more for operational/tactical issues while SD is used more for strategic issues we compare the cumulative percentage use of DES and SD along the ranked list of LSCM issues presented in Figure 1. The cumulative percentage lines are shown in Figure 4. Our expectation is that the SD line would rise quickly and then level off, signifying greater use on strategic issues, while the DES line would show the opposite pattern. A close fit would signify little or no difference in terms of use on strategic and operational/tactical issues. 


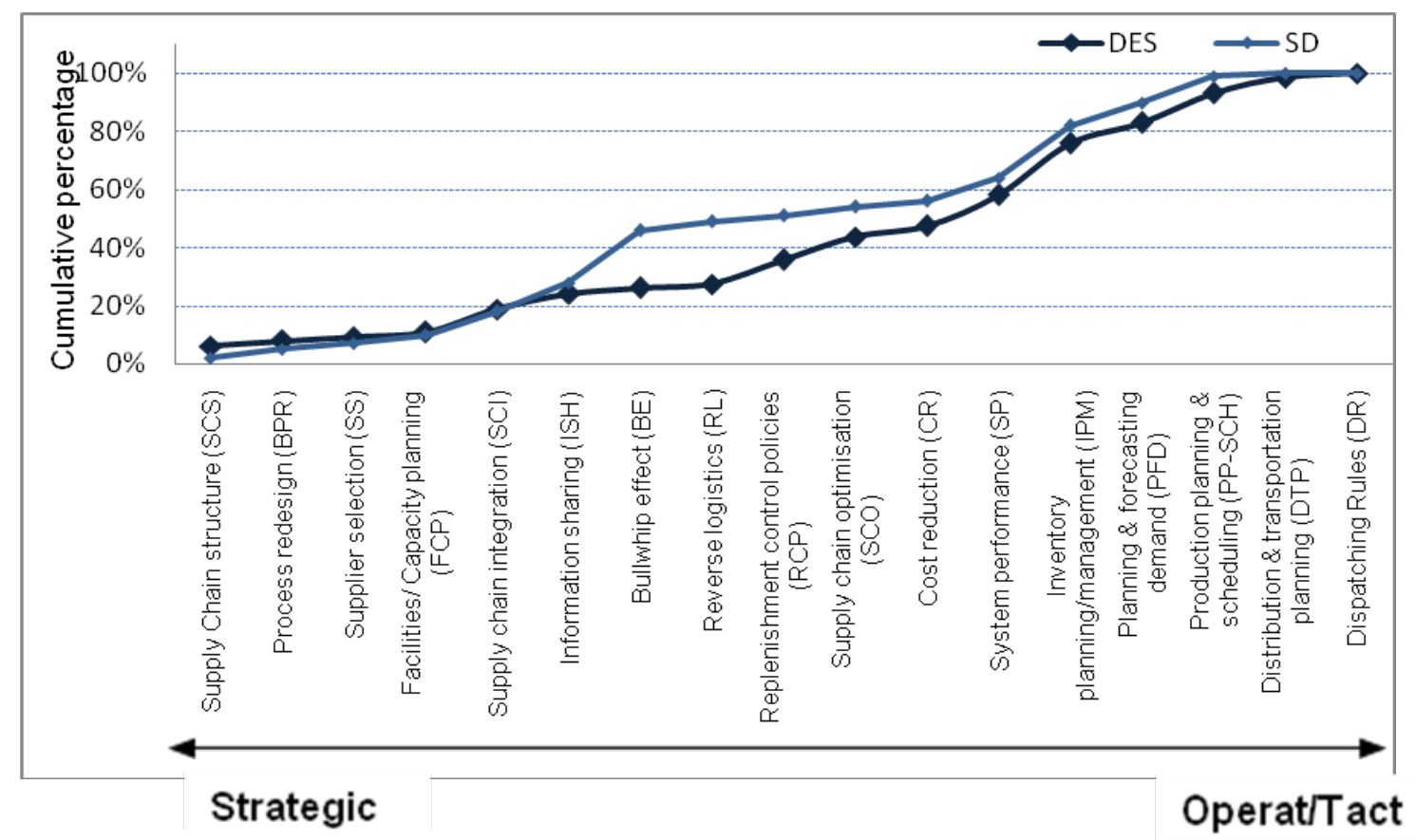

Figure 4: Cumulative percentage use of DES and SD by LSCM issue

Figure 4 shows that the two lines seem to fit quite closely for the issues at the strategic end of the spectrum (left-hand end of the graph). The lines then separate around the middle of the graph as the spectrum moves towards operational/tactical issues. There is a step change in the SD line at the "bullwhip effect", after which the lines gradually narrow. This is not surprising given the level of interest in the bullwhip effect in the SD literature, particularly based around the beer distribution game [136].

A chi-square test shows that these distributions are significantly different at a $95 \%$ level $(\chi=$ $50.71, p=0.00001)$. Since the SD line runs just above the DES line, this suggests that SD models have a slightly more strategic focus, albeit that the lines largely overlap for the issues at the very left of the graph. The main difference occurs at the bullwhip effect. If the bullwhip effect is removed from the data, a similar chi-square test shows that the distributions are not significantly different at $95 \%$ level $(\chi=19.7, p=0.233)$. This suggests that with the exception of the bullwhip effect there is no significant difference in the use of DES and SD on a strategic or operational/tactical level.

From the cumulative percentages displayed in Figure 4 a relatively low use of DES and SD for modelling strategic LSCM issues can be observed. Depending on where the spectrum moves from strategic to operational/tactical issues, the use of DES and SD for strategic issues might be as low as around 20\% to 30\% of modelling applications (cut-off at "information sharing”). 


\section{Summary of findings}

DES and SD have both been used to model DSS for a wide range of LSCM issues. Based on the journal papers identified in the review period (1996-2006), DES is used more frequently than SD for supply chain modelling. The use of DES in the LSCM context is also growing at a faster rate.

For most LSCM issues DES is used more frequently with the exception of the bullwhip effect. Compared to SD modelling, DES is used relatively more frequently to address LSCM issues such as supply chain structure, supply chain integration, replenishment control policies, supply chain optimisation, cost reduction, system performance, inventory planning \& management, planning and forecasting demand, production planning \& scheduling, distribution and transportation planning and dispatching rules.

Within each modelling approach, the percentage use identifies which issues each modelling approach focus on most. For DES there is a significantly greater focus on: supply chain structure, replenishment control policies, supply chain optimisation, distribution \& transport planning, and dispatching rules. For SD the only significantly greater focus is on the bullwhip effect. For all other LSCM issues the percentage use of DES and SD is similar (there is no significant difference).

The findings on the use of DES and SD are summarised in Table 5. The LSCM issues are grouped into 4 categories: common (DES, SD) domain, DES domain, SD domain, less common (DES, SD) domain. The issues are categorised using primarily the percentage of modelling activity undertaken in each modelling approach by LSCM issue. The bottom left and top right quadrants, DES/SD domain include LSCM issues for which the analysis has identified a significantly higher modelling activity for the DES or SD approach respectively. The remaining two categories, common or less common domain include LSCM issues for which the analysis revealed a similar (no significant difference) modelling activity undertaken between the two modelling approaches. The distinction between the two categories is based on the total number of papers identified for both approaches. For LSCM issues where a relatively large modelling frequency is identified (for example supply chain integration has 29 overall applications), they are categorised as being in the common domain, whereas for others that have a relatively small number of total applications up to 12 in total (for example business process engineering with a total of 8 applications), these are included in the less common domain category. The latter category also includes issues that have not 
been tackled by either approach (in brackets). These issues have been identified in nonsimulation papers that undertake analytic modelling of LSCM.

Table 5: Classification of LSCM issues into domain areas based on the frequency modelled by each modelling approach

\begin{tabular}{|l|l|l|}
\hline & SD high frequency of use & SD low frequency of use \\
\hline $\begin{array}{l}\text { DES high } \\
\text { frequency of use }\end{array}$ & $\begin{array}{l}\text { Common (DES \& SD) domain } \\
\text { Supply chain integration (SCI) } \\
\text { Information sharing (ISH) } \\
\text { System performance (SP) } \\
\text { Inventory planning/ management } \\
\text { (IPM) } \\
\text { Planning \& forecasting demand } \\
\text { (PFD) }\end{array}$ & $\begin{array}{l}\text { DES domain } \\
\text { Supply chain structure (SCS) } \\
\text { Replenishment control policies (RCP) } \\
\text { Supply chain optimisation (SCO) } \\
\text { Distribution \& transportation planning } \\
\text { (DTP) }\end{array}$ \\
$\begin{array}{ll}\text { Production planning \& scheduling } \\
\text { (PP-SCH) }\end{array}$ & \\
\hline $\begin{array}{l}\text { DES low } \\
\text { frequency of use }\end{array}$ & $\begin{array}{l}\text { SD domain } \\
\text { Bullwhip effect (BE) }\end{array}$ & $\begin{array}{l}\text { Less common (to DES \& SD) domain } \\
\text { Process redesign (BPR) } \\
\text { Supplier Selection (SS) } \\
\text { Facilities/ capacity planning (FCP) } \\
\text { Reverse logistics (RL) } \\
\text { Cost reduction (CR) } \\
\text { Dispatching rules (DR) } \\
\text { (Pricing policies) } \\
\text { (Return policies) } \\
\text { (Global supply chain) }\end{array}$ \\
& &
\end{tabular}

In terms of application of DES and SD to support decisions at a strategic or operational/ tactical level, there is little evidence of any difference within the LSCM context. It may be that SD, when it is used, is marginally used proportionately more often for strategic issues. Overall, DES and SD are used more frequently to model operational/tactical issues in the LSCM context. Indeed, in light of the categorisation of issues in Table 5, the common domain category includes only two strategic issues (supply chain integration and information sharing) with the rest being mainly operational/ tactical. The DES domain again includes mostly operational tactical issues, with the exception of supply chain structure, whereas the SD domain again includes the bullwhip effect which can be considered more at a strategic level. The majority of the strategic LSCM issues are categorised as part of the less common domain, suggesting that the use of simulation for strategic issues in the LSCM context is generally low.

We would note that there is very little evidence for the use of hybrid-DES/SD modelling for supply chains. This may be an area of future development. 
Based on the findings summarised above, we can now turn our attention to assess the appropriateness of using DES and SD as DSS tools in LSCM. Evidently, DES and SD are capable of modelling the complexity and uncertainty inherent in the LSCM environment. They are powerful techniques that can be integrated in DSS of LSCM to undertake "what if" analysis with a wide range of scenarios. The analysis undertaken in this paper shows that DES and SD can be used interchangeably in DSS to address a number of problems at the operational/tactical level, including: information sharing, system performance, inventory planning/management, planning \& forecasting demand and production planning \& scheduling. DES, however, appears to be most suited to replenishment control policies, supply chain optimisation and distribution \& transportation planning.

At the strategic level the issue of supply chain integration can be modelled using both approaches. Meanwhile, there are a number of strategic issues such as process redesign, supplier selection and facilities/capacity planning where we found only limited use of DES and SD. These issues can be addressed, at least to a degree, by methods other than simulation, for instance, optimisation methods can be used in model based DSS for process redesign, and location and capacity planning [24]. Some strategic LSCM issues appear to be more amenable to only one of the simulation approaches, for instance, the bullwhip effect (SD) and supply chain structure (DES).

What emerges is a limited polarisation in the use of DES and SD for LCSM. This lack of a clear pattern could be in line with the findings from a recent empirical study on users' perceptions of a DES and SD model of the same problem [140]. This study found that the two models were not perceived as significantly different, implying that from the user's point of view the type of simulation approach makes little, if any, difference as long as it is suitable for addressing the problem situation at hand. Based on these considerations, it can be concluded that the majority of LSCM issues (at the strategic and tactical/operational level) can be modelled by both simulation approaches, and that there are only a few issues which might remain the sole preserve of just DES or SD. There are, however, differing degrees of use across the LSCM issues, which suggests some preference for one approach over another. Of course, in selecting a simulation approach for a model based DSS in LSCM, consideration also needs to be given to a wider set of criteria than just the issue to be modelled [15].

\section{Conclusion}

The findings of this study bring useful insights about different simulation approaches used as decision support systems in the field of supply chain modelling. It is a novel study that 
provides evidence about the extent and use of DES and SD modelling in the LSCM context, contributing to the limited literature that compares DES and SD. This paper explores the use of DES and SD as modelling tools used to support decision making in the LSCM context. This is done with respect to the nature and level of problems considered. Journal articles published between 1996 and 2006 that describe the application of DES and SD in LSCM issues were reviewed. The analysis undertaken sheds light on the two questions initially posed.

The first question asked whether DES and SD are used to model different LSCM issues. The findings show that both simulation approaches have been used to model the majority of LSCM issues identified, albeit to differing extents. It was established that the DES approach has been used more frequently compared to SD. The LSCM issues were then classified into four categories based on a comparison of the percentage of modelling activity in each modelling approach. The result is presented in Table 5 in which the LSCM issues are categorised as belonging to either the DES domain, SD domain, the common domain (frequently modelled using both approaches) or the less common domain (modelled using both approaches, but infrequently). This suggests that while there are a number of issues in LSCM that may lend themselves to one specific modelling approach, other modelling issues lie in a range between the two extremes and can be modelled using either approach.

The second question asked whether DES is used more at an operational/tactical level and SD more at strategic level. No evidence was found to support the belief that DES is used more for operational/tactical issues, whereas SD for strategic problems. On the contrary no difference was found in the extent of DES/SD modelling on a strategic or operational/tactical level.

The findings of this study are defined by the sample of journals chosen, but also the approach and the setting in which the study has been undertaken. For example, the literature review is based on peer reviewed journals only. Journal articles, which by nature are more academic than practice based, might not reflect the full range and frequency of use of DES and SD in the LSCM context. Meanwhile, the LSCM context may by nature be more operational than strategic, and this would affect the picture presented by this study. Furthermore, the study has not considered the success of the models in addressing the LSCM issues, i.e. did the SD models address an issue better than the DES models, or vice versa? This would be difficult to 
establish because detailed information about the models and their impact is not always made readily available in the papers.

As well as providing some interesting results, this study provides the basis for further comparison studies. Future work could expand on this study as well as address the limitations discussed above. Grey literature and conference papers could be used to undertake a similar review of supply chain simulation models and to provide a more practice based focus. This paper takes a literature-based approach to identifying the LSCM issues modelled using DES and SD, and it does not consider the other criteria used in choosing the simulation approach. This type of information is not provided by published papers. The research presented here could be extended to consider the criteria that affect the choice of modelling approach for specific modelling projects by interviewing modellers to gain access to more detailed information on their choice of approach. This might also make a review of the success of the models possible. Future work could also undertake a similar analysis in other areas of application, such as health care, insurance and education; and compare the findings. 


\section{Appendix 1: List of selected papers categorised by LSCM issues and simulation approach}

Table 6: List of LSCM papers selected for the literature review

\begin{tabular}{|c|c|c|c|c|c|c|c|c|c|c|c|c|c|c|c|c|c|c|}
\hline No & Article & BE & PFD & ISH & IPM & $\begin{array}{l}\text { PP- } \\
\text { SCH }\end{array}$ & DTP & BPR & CP & DR & SP & RCP & $\mathrm{SCl}$ & SCS & SS & CR & sco & $\mathbf{R L}$ \\
\hline 1 & Alfieri and Brandimarte 1997 [1] & & & & DES & & & & & & & & DES & DES & & & & \\
\hline 2 & Ali et al.1999 [2] & & & & & DES & & & & & & & & & & & & \\
\hline 4 & Anderson and Morrice 2000 [3] & & & SD & & & & & & & & & & & & & & \\
\hline 5 & Andeson et al. 2000 [5] & $\mathrm{SD}$ & & & & & & & & & & & & & & & & \\
\hline 6 & Angulo et al. 2004 [7] & & DES & DES & DES & DES & & & & & & DES & & & & & & \\
\hline 7 & Ashayeri and Lemmes 2006 [8] & & SD & & & & & & & & & & & & & & & \\
\hline 9 & Berry and Naim 1996 [11] & $\mathrm{SD}$ & & SD & SD & SD & & SD & & & & & SD & & & & & \\
\hline 10 & Bhaskaran 1998 [12] & DES & & & & & & & & & & & DES & DES & & & & \\
\hline 11 & Biswas and Narahari 2004 [13] & & & & DES & & & & DES & & & & & & & & DES & \\
\hline 12 & Ceroni and Nof 2005 [19] & & DES & DES & & & & DES & & & & & DES & & & & & \\
\hline 13 & Ceroni and Nof 2002 [20] & & DES & DES & DES & DES & & & & & & & & & & & & \\
\hline 14 & Caputo et al.2003 [18] & & & & & & DES & & DES & & & & & & & & & \\
\hline 15 & Chan and Chan 2005 [21] & & & & & & & & & & & & & & & DES & DES & \\
\hline 16 & Byrne and Heavey 2006a [17] & & & & & & & & & & & & DES & & & & DES & \\
\hline 18 & Cheng and Duran 2004 [23] & & & & DES & & DES & & & & & & & & & & DES & \\
\hline 19 & Cigolini et al. 1999 [25] & & & & & DES & & & & DES & & & & & & & & \\
\hline 20 & D'Alessandro and Baveja 2000 [28] & SD & & SD & & & & & & & & & & & & & & \\
\hline 21 & Dejonckheere et al.2002 [29] & & & & & DES & & DES & & & & & & & & & & \\
\hline 22 & Croson and Donohue 2003 [27] & SD & SD & & & & & & & & & & & & & & & \\
\hline 23 & Ding et al.2006 [31] & & & & & DES & & & & & & & & & DES & & DES & \\
\hline 24 & Ding et al. 2005 [30] & & & & & DES & DES & & DES & & & & & DES & DES & & DES & \\
\hline 25 & Disney et al. 2004 [32] & & & SD & & & & & & & & & & SD & & & & \\
\hline 26 & Disney et al. 2003 [33] & & & & $\mathrm{SD}$ & & SD & & & & & & SD & & & SD & & \\
\hline 27 & Disney and Towill 2002 [34] & & SD & & SD & & & & & & & & SD & & & & & \\
\hline 28 & Disney and Towill 2003a [35] & SD & & & SD & & & & & & & & SD & & & & & \\
\hline 29 & Disney and Towill 2003b [36] & SD & & & & & & & & & & & SD & & & & & \\
\hline
\end{tabular}




\begin{tabular}{|c|c|c|c|c|c|c|c|c|c|c|c|c|c|c|c|c|c|c|}
\hline No & Article & BE & PFD & ISH & IPM & $\begin{array}{l}\text { PP. } \\
\text { SCH }\end{array}$ & DTP & BPR & CP & DR & SP & RCP & $\mathrm{SCl}$ & SCS & ss & CR & SCO & $\mathbf{R L}$ \\
\hline 30 & Disney and Towill 2003c [37] & SD & & & SD & & & & & & & SD & & & & & & \\
\hline 31 & Dong and Chen 2005a [38] & & & & & & & & & & & & & DES & & & & \\
\hline 32 & Dong and Chen 2005b [39] & & & & DES & & & & & & & & & DES & & & DES & \\
\hline 33 & Fiala 2005 [40] & & & SD & & & & & & & & & SD & & & & & \\
\hline 34 & Fleisch and Tellkamp 2005 [41] & & & DES & DES & & & & & & & & DES & & & & & \\
\hline 35 & Fleischmann et al 2003 [42] & & & & DES & & & & & & & DES & & DES & & DES & & DES \\
\hline 36 & Fowler 1998 [43] & & & & & & & SD & & & & & & & & & & \\
\hline 38 & Garavelli 2003 [45] & & & & & DES & DES & & & & & & DES & & & & DES & \\
\hline 39 & Georgiadis and Vlachos 2004 [46] & & SD & & & SD & & & & & SD & & & & & & & SD \\
\hline 40 & Georgiadis et al. 2005 [47] & & & & SD & & & & SD & & & & & & & & & \\
\hline 41 & Georgiadis et al.2006 [48] & & SD & & & & & & SD & & SD & & & & & & & SD \\
\hline 42 & Giannoccaro and Pontrandolfo 2002 [49] & & & & DES & & & & & & & & DES & & & & & \\
\hline 43 & Giannoccaro et al.2003 [50] & & & & DES & & & & & & & & DES & & & & & \\
\hline 44 & Gnoni et al. 2003 [51] & & & & & DES & & & & & DES & & & & & & DES & \\
\hline 45 & Gobel and Hocke 2001 [52] & & & & & & & & & & & & DES & & & & & \\
\hline 47 & Guerrin 2004 [55] & & & & SD & & & & & & & SD & & & SD & & SD & \\
\hline 48 & Gupta et al 2002 [56] & & & & DES & DES & & & & & DES & & & & & & & \\
\hline 49 & Hafeez et al.1996 [57] & & & & SD & SD & & SD & & & SD & & & & & & & \\
\hline 50 & Helo 2000 [60] & SD & & & SD & & & & SD & & & & & & & & & \\
\hline 51 & Hieber and Hartel 2003 [61] & DES & & & DES & & & & & & & & & & & & & \\
\hline 52 & Higuchi and Troutt 2004 [62] & SD & SD & & & & & & & & & & & & & & & \\
\hline 53 & Holweg and Bicheno 2002 [63] & & SD & & SD & SD & & & & & & & & SD & & & & \\
\hline 54 & Holweg et al. 2005 [64] & SD & & & SD & & & & & & & & & & & & & \\
\hline 55 & Hung et al. 2004 [65] & & DES & & DES & & & & & & & DES & & & & & & \\
\hline 56 & Hwarng et al. 2005 [66] & & DES & & DES & & & & & & & & & DES & & & & \\
\hline 57 & Ingalls et al. 2005 [68] & DES & & & & & & & & & & & & & & & & \\
\hline 58 & Jain and Ervin 2005 [69] & & DES & & DES & & & & & & DES & DES & & & DES & & & \\
\hline 59 & Jansen et al. 2001 [70] & & & & DES & & DES & & & & DES & & & & & & DES & \\
\hline 60 & Jeong et al. 2006 [71] & & & & DES & & & & & & DES & & & DES & & & DES & \\
\hline 61 & Jung et al. 2005 [72] & & & DES & & DES & & & DES & & & & DES & & & & & \\
\hline 62 & Karabakal et al. 2000 [73] & & & & DES & & DES & DES & & & & & & DES & & DES & DES & \\
\hline 63 & Koh and Gunasekaran 2006 [74] & & DES & & DES & DES & & & & & DES & & & & & & & \\
\hline
\end{tabular}




\begin{tabular}{|c|c|c|c|c|c|c|c|c|c|c|c|c|c|c|c|c|c|c|}
\hline No & Article & BE & PFD & ISH & IPM & $\begin{array}{l}\text { PP. } \\
\text { SCH }\end{array}$ & DTP & BPR & CP & DR & SP & RCP & SCl & SCS & SS & CR & ScO & $\mathbf{R L}$ \\
\hline 65 & Larsen et al. 1999 [78] & SD & & & SD & & & & & & & & & & & & & \\
\hline 66 & Lee et al. 2002 [81] & & & & HYB & HYB & & & HYB & & & HYB & & & & & & \\
\hline 67 & Lee and Kim 2002 [82] & & & & & DES & DES & & & & & & & & & DES & DES & \\
\hline 68 & Liberopoulos and Koukoumialos 2005 [84] & & & & DES & DES & & & & & & & & DES & & & & \\
\hline 69 & Lim et al. 2006a [85] & & & & DES & DES & & & & & DES & DES & & & & & DES & \\
\hline 70 & Lim et al. 2006b [86] & & & & & & DES & & & & & & & & & & DES & \\
\hline 71 & Lin et al. 2000 [87] & & & & DES & DES & & & & & DES & DES & & & & & DES & \\
\hline 72 & Lo Nigro et al. 2003 [88] & & & & & DES & & & & & & & DES & & & & & \\
\hline 73 & Lu et al. 2005 [89] & & & DES & & & & & & & DES & & & & & DES & & \\
\hline 74 & Machuca and Barajas 2004 [90] & SD & & SD & & & & & & & SD & & & & & SD & & \\
\hline 75 & Marquez et al.2004 [91] & & & SD & & & & & & & SD & & SD & & & & & \\
\hline 76 & Marquez and Blanchar 2004 [92] & & & & & & & & & & & & & & SD & & SD & \\
\hline 77 & Mason-Jones and Towill 1999 [93] & & & SD & & & & & & & & & & & & & & \\
\hline 78 & Mason et al. 2003 [94] & & & & DES & & & & & DES & & DES & DES & & & & & \\
\hline 79 & Mertins et al. 2005 [95] & & & & & & & & & & & & DES & & & & & \\
\hline 80 & Metz et al. 2004 [96] & & & & DES & & & & & & & & & & & & DES & \\
\hline 81 & Minegishi and Thiel 2000 [97] & SD & & & SD & SD & & & & & & & & & & & & \\
\hline 82 & Moon and Kim 2005 [98] & SD & & & & & & & & & & & & & & & & \\
\hline 83 & Myers and Richards 2003 [101] & & & & DES & & & & & & DES & & & & & DES & & \\
\hline 84 & Naim $2006[102]$ & SD & & & SD & SD & & & & & SD & & & & & & & \\
\hline 85 & Olhager and Persson 2006 [105] & & & & DES & DES & & & & & & & & & & & & \\
\hline 86 & Ovalle and Marquez 2003 [107] & & & & SD & SD & & & & & & & SD & & & & & \\
\hline 87 & Ozbayrak et al. 2006 [109] & & & & & DES & & & & & & & & & & & & \\
\hline 88 & Persson and Olhager 2002 [110] & & & & DES & DES & & & & & DES & & & DES & & & & \\
\hline 89 & Petrovic 2001 [111] & & DES & & DES & & & & & & & & & & & & & \\
\hline 90 & Petrovic et al. 1999 [112] & & DES & & DES & & & & & & DES & DES & & & & & & \\
\hline 91 & Petrovic et al. 1998 [113] & & DES & & DES & & & & & & DES & & & & & & & \\
\hline 92 & Rafaeli and Ravid 2003 [117] & & & SD & SD & & & & & & & & & & & & & \\
\hline 93 & Rao et al. 2003 [118] & & & & DES & & & & & & & & DES & & & & & \\
\hline 94 & Rathore et al. 2005 [119] & & & & & & & & & & & & DES & & & & & \\
\hline 95 & Ravulapati et al.2004 [120] & & & & DES & & & & & & & & DES & & & & & \\
\hline 96 & Reiner 2005 [121] & & & & & HYB & & HYB & & & HYB & & HYB & & & & & \\
\hline 97 & Reiner and Trcka 2004 [122] & DES & DES & DES & & & & & & & DES & DES & & DES & & & & \\
\hline 98 & Rios and Stuart 2004 [125] & & & & & DES & & & & & & DES & & & & & & DES \\
\hline
\end{tabular}




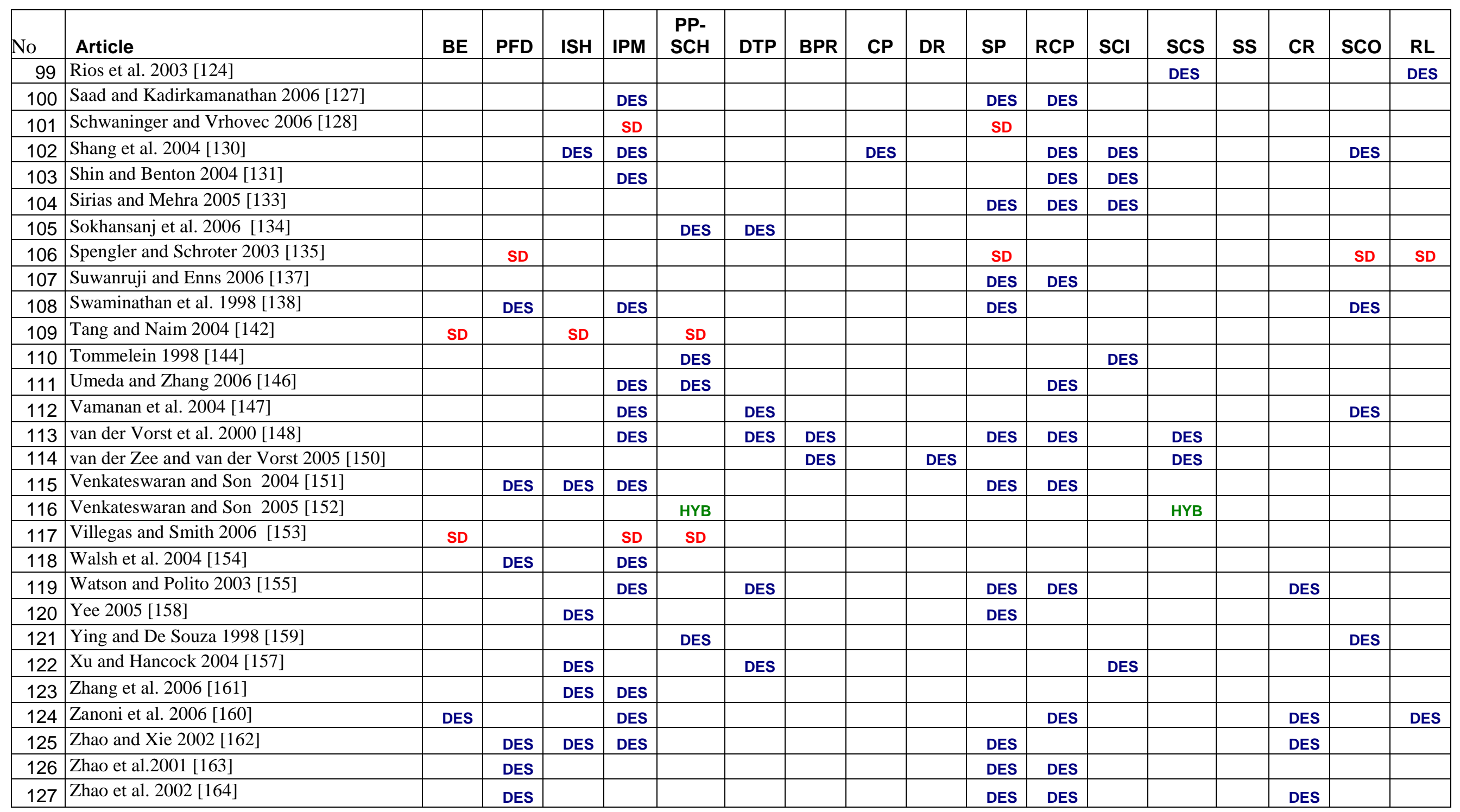




\section{Appendix 2: The LSCM issues explained}

\begin{tabular}{|c|c|}
\hline LSCM issues & Brief explanation \\
\hline Supply chain structure & $\begin{array}{l}\text { Designing the supply chain structure refers to the configuration } \\
\text { of the chain, the sequential links between different activities or } \\
\text { processes. Typical decisions made are related to the flow of } \\
\text { materials between stages, involvement or not of intermediaries, } \\
\text { pull versus push configurations, etc. }\end{array}$ \\
\hline Process redesign & $\begin{array}{l}\text { Supply chain redesign or re-engineering involves changes in its } \\
\text { structure (facilities, production processes, transportation) and } \\
\text { processes. An emerging stream of work in this category explores } \\
\text { the streamlining of physical transformation processes to simplify } \\
\text { the decision-making and control to eradicate waste, such as: } \\
\text { Total Quality Management, Just-in-Time, Kaizen etc. Supply } \\
\text { chain redesign is associated with strategic management as it } \\
\text { requires an overall understanding of business processes. }\end{array}$ \\
\hline Supplier selection & $\begin{array}{l}\text { Related to procurement that is the process of purchasing raw } \\
\text { materials needed to make finished goods or to support the } \\
\text { operations of a firm. The selection of intermediaries or suppliers } \\
\text { is made based on the evaluation of procurement bids for multiple } \\
\text { products or suppliers. }\end{array}$ \\
\hline $\begin{array}{l}\text { Facilities/capacity } \\
\text { planning/utilisation }\end{array}$ & $\begin{array}{l}\text { Typical decisions are the determination of the facility role and } \\
\text { processes to be performed, facility location and capacity } \\
\text { allocation, etc. These decisions are usually linked with the } \\
\text { objectives and long term vision of the firms or partners in the } \\
\text { chain and hence considered a strategic issue. }\end{array}$ \\
\hline System performance & $\begin{array}{l}\text { The performance of the supply chain is evaluated using a } \\
\text { number of criteria, such as transportation cost, resources } \\
\text { utilization, inventory level, order cycle time, delivery } \\
\text { performance, etc. }\end{array}$ \\
\hline Bullwhip effect & $\begin{array}{l}\text { The phenomenon of upstream order magnification in the supply } \\
\text { chain. Due to the fluctuations, supply chain partners do not } \\
\text { receive a reliable picture of inventory levels which results into a } \\
\text { poor alignment between demand and production patterns across } \\
\text { echelons. }\end{array}$ \\
\hline Supply chain integration & $\begin{array}{l}\text { Supply chain integration enables the cooperation of two or more } \\
\text { systems in pursuit of complementary objectives. This category } \\
\text { includes a number of coordination mechanisms such as: vendor } \\
\text { managed inventory, quantity discounts, quantity flexibility, } \\
\text { allocation rules, quick response, strategic partnerships, etc. }\end{array}$ \\
\hline Information sharing & $\begin{array}{l}\text { Information sharing strategies are introduced as a sub-set of } \\
\text { supply chain integration mechanisms, which aim to reduce the } \\
\text { bullwhip effect and to improve the supply chain performance. } \\
\text { Some of the hurdles encountered in operationalising these } \\
\text { strategies are the reluctance of firms to share information on } \\
\text { sales, demand, production and delivery, inventory levels, etc. } \\
\text { This is considered as a separate category, due to the large } \\
\text { number of papers on information sharing. }\end{array}$ \\
\hline Supply chain optimisation & $\begin{array}{l}\text { Supply chain optimisation is mainly concerned with the } \\
\text { identification of optimal policies that optimise key performance } \\
\text { indicators, such as profits, costs, product flows, etc. }\end{array}$ \\
\hline Cost reduction & $\begin{array}{l}\text { Cost reduction is often the incentive of various policies } \\
\text { undertaken such as electronic data interchange, inventory }\end{array}$ \\
\hline
\end{tabular}




\begin{tabular}{|c|c|}
\hline & management, etc. \\
\hline Replenishment control policies & $\begin{array}{l}\text { These policies deal with the control of stock levels in the } \\
\text { echelons of the supply chain and the ordering policy. The aim is } \\
\text { to have the right product quantity at the right location and at the } \\
\text { right time. The choice of inventory replenishment policies aims } \\
\text { to achieve low inventory while maintaining high delivery } \\
\text { performance. }\end{array}$ \\
\hline $\begin{array}{l}\text { Inventory planning/ } \\
\text { management }\end{array}$ & $\begin{array}{l}\text { Deals with the management and movement of goods throughout } \\
\text { the supply chain. Studies on inventory planning and } \\
\text { management focus on optimisation of service levels or process } \\
\text { time by varying the location or quantity of inventory. In each } \\
\text { echelon, a decision is made to manage the inventory based on } \\
\text { inventory levels, holding and backlog costs and replenishment } \\
\text { control policies. }\end{array}$ \\
\hline Planning \& Forecasting demand & $\begin{array}{l}\text { It can be the primary or secondary focus of simulation studies, } \\
\text { where the objective is to anticipate or to mitigate the risks } \\
\text { involved. These models generate forecasts of the expected future } \\
\text { demand and investigate the impact of major demand changes on } \\
\text { supply chain echelons. }\end{array}$ \\
\hline $\begin{array}{l}\text { Production planning \& } \\
\text { scheduling }\end{array}$ & $\begin{array}{l}\text { Production planning \& scheduling deals with the management of } \\
\text { manufacturing processes and the policies that determine the } \\
\text { configuration of the production sequence and resource allocation, } \\
\text { material handling, scheduling of machines and work centres. } \\
\text { Simulation models are often concerned with the effect of } \\
\text { different production planning rules on supply chain performance. }\end{array}$ \\
\hline $\begin{array}{l}\text { Distribution \& transportation } \\
\text { planning }\end{array}$ & $\begin{array}{l}\text { Deals with the physical movement of inventory (products, } \\
\text { materials) from one stage of the supply chain to another. Some } \\
\text { decisions made are: the design of the transportation network, } \\
\text { choice of transportation models, the management of vehicle fleet } \\
\text { (routing and scheduling), etc. }\end{array}$ \\
\hline Dispatching rules & $\begin{array}{l}\text { Dispatching rules deal with decisions made regarding the } \\
\text { fulfilment of specific customer orders, considering on one-hand } \\
\text { delivery dates and on the other hand utilisation of the } \\
\text { manufactures' shop floor. }\end{array}$ \\
\hline Reverse logistics & $\begin{array}{l}\text { Reverse logistics is concerned with the recovery of products as } \\
\text { spare parts or recycled products at the end of their life cycle. } \\
\text { Product recovery is driven by economical and environmental } \\
\text { incentives, which at the same time affects companies’ } \\
\text { manufacturing and collection activities. }\end{array}$ \\
\hline
\end{tabular}




\section{References}

[1] A. Alfieri and P. Brandimarte, "Object-oriented modeling and simulation of integrated production/distribution systems," Computer Integrated Manufacturing Systems, vol. 10, pp. 261-266, Oct 1997.

[2] S. A. Ali, et al., "Intelligent simulation environment for printed circuit board assembly," Journal of Electronics Manufacturing, vol. 9, pp. 299-311, Dec 1999.

[3] E. G. Anderson and D. J. Morrice, "A simulation came for teaching service-oriented supply chain management: Does information sharing help managers with service capacity decisions?," Production and Operations Management, vol. 9, pp. 40-55, Spr 2000.

[4] E. G. Anderson, et al., "The "physics"' of capacity and backlog management in service and custom manufacturing supply chains," System Dynamics Review, vol. 21, pp. 217-247, Fal 2005.

[5] E. G. Andeson, et al., "Upstream volatility in the supply chain: The machine tool industry as a case study," Production and Operations Management, vol. 9, pp. 239261, Fal 2000.

[6] B. Angerhofer and M. Angelides, "System Dynamics Modelling in Supply Chain Management: Research Review," in 2000 Winter Simulation Conference, 2000, pp. 342-351.

[7] A. Angulo, et al., "Supply Chain Information Sharing in a Vendor Managed Inventory Partnership," Journal of Business Logistics, vol. 25, pp. 101-120, 2004.

[8] J. Ashayeri and L. Lemmes, "Economic value added of supply chain demand planning: A system dynamics simulation," Robotics and Computer-Integrated Manufacturing, vol. 22, pp. 550-556, Oct-Dec 2006.

[9] T. S. Baines and D. K. Harrison, "An opportunity for system dynamics in manufacturing system modelling," Production Planning \& Control, vol. 10, pp. 542552, Sep 1999.

[10] B. M. Beamon and V. C. P. Chen, "Performance analysis of conjoined supply chains," International Journal of Production Research, vol. 39, pp. 3195-3218, Sep 2001.

[11] D. Berry and M. M. Naim, "Quantifying the relative improvements of redesign strategies in a PC supply chain," International Journal of Production Economics, vol. 46, pp. 181-196, Dec 1996.

[12] S. Bhaskaran, "Simulation analysis of a manufacturing supply chain," Decision Sciences, vol. 29, pp. 633-657, Sum 1998.

[13] S. Biswas and Y. Narahari, "Object oriented modeling and decision support for supply chains," European Journal of Operational Research, vol. 153, pp. 704-726, Mar 2004.

[14] S. Brailsford and N. Hilton, "A Comparison of Discrete Event Simulation and System Dynamics for Modelling Healthcare Systems," in Proceedings of the 26th meeting of the ORAHS Working Group 2000, Glasgow, Scotland, 2001, pp. 18-39.

[15] A. Brennan, et al., "A taxonomy of model structures for economic evaluation of health technologies," Health economics, vol. 15, pp. 1295-1310, 2006.

[16] P. J. Byrne and C. Heavey, "The impact of information sharing and forecasting in capacitated industrial supply chains: A case study," International Journal of Production Economics, vol. 103, pp. 420-437, Sep 2006b.

[17] P. J. Byrne and C. Heavey, "Simulation model of a vertically integrated supply chain: A case study," International Journal of Industrial Engineering-Theory Applications and Practice, vol. 13, pp. 126-135, Jun 2006a.

[18] A. C. Caputo, et al., "Integrating transport systems in supply chain management software tools," Industrial Management \& Data Systems, vol. 103, pp. 503-515, 2003. 
[19] J. A. Ceroni and S. Y. Nof, "Task parallelism in distributed supply organizations: a case study in the shoe industry," Production Planning \& Control: The Management of Operations, vol. 16, pp. 500 - 513, 2005.

[20] J. A. Ceroni and S. Y. Nof, "A workflow model based on parallelism for distributed organizations," Journal of Intelligent Manufacturing, vol. 13, pp. 439-461, Nov 2002.

[21] F. T. S. Chan and H. K. Chan, "Simulation modeling for comparative evaluation of supply chain management strategies," International Journal of Advanced Manufacturing Technology, vol. 25, pp. 998-1006, May 2005.

[22] F. T. S. Chan and H. K. Chan, "The future trend on system-wide modelling in supply chain studies," International Journal of Advanced Manufacturing Technology, vol. 25, pp. 820-832, 2005.

[23] L. F. Cheng and M. A. Duran, "Logistics for world-wide crude oil transportation using discrete event simulation and optimal control," Computers \& Chemical Engineering, vol. 28, pp. 897-911, Jun 2004.

[24] S. Chopra and P. Meindl, Supply Chain Management: Strategy, Planning and Operation, 3rd ed. New Jersey: Prentice Hall, 2007.

[25] R. Cigolini, et al., "Implementing new dispatching rules at SGS-Thomson microelectronics," Production Planning \& Control, vol. 10, pp. 97-106, Jan-Feb 1999.

[26] W. C. Copacino, Supply chain management : the basics and beyond / William C. Copacino. Boca Raton, Fla. : Falls Church, Va. :: St. Lucie Press ; APICS, 1997.

[27] R. Croson and K. Donohue, "Impact of POS data sharing on supply chain management: An experimental study," Production and Operations Management, vol. 12, pp. 1-11, Spr 2003.

[28] A. J. D'Alessandro and A. Baveja, "Divide and conquer: Rohm and Haas' response to a changing specialty chemicals market," Interfaces, vol. 30, pp. 1-16, Nov-Dec 2000.

[29] J. Dejonckheere, et al., "Transfer function analysis of forecasting induced bullwhip in supply chains," International Journal of Production Economics, vol. 78, pp. 133-144, Jul 2002.

[30] H. W. Ding, et al., "A simulation optimization methodology for supplier selection problem," International Journal of Computer Integrated Manufacturing, vol. 18, pp. 210-224, Mar-May 2005.

[31] H. W. Ding, et al., "A simulation-based multi-objective genetic algorithm approach for networked enterprises optimization," Engineering Applications of Artificial Intelligence, vol. 19, pp. 609-623, Sep 2006.

[32] S. M. Disney, et al., "Assessing the impact of e-business on supply chain dynamics," International Journal of Production Economics, vol. 89, pp. 109-118, May 2004.

[33] S. M. Disney, et al., "The impact of vendor managed inventory on transport operations," Transportation Research Part E-Logistics and Transportation Review, vol. 39, pp. 363-380, Sep 2003.

[34] S. M. Disney and D. R. Towill, "A discrete transfer function model to determine the dynamic stability of a vendor managed inventory supply chain," International Journal of Production Research, vol. 40, pp. 179-204, Jan 2002.

[35] S. M. Disney and D. R. Towill, "The effect of vendor managed inventory (VMI) dynamics on the Bullwhip Effect in supply chains," International Journal of Production Economics, vol. 85, pp. 199-215, Aug 2003a.

[36] S. M. Disney and D. R. Towill, "Vendor-managed inventory and bullwhip reduction in a two-level supply chain," International Journal of Operations \& Production Management, vol. 23, pp. 625-651, 2003b. 
[37] S. M. Disney and D. R. Towill, "On the bullwhip and inventory variance produced by an ordering policy," Omega-International Journal of Management Science, vol. 31, pp. 157-167, Jun 2003c.

[38] M. Dong and F. F. Chen, "The impacts of component commonality on integrated supply chain network performance: a state and resource-based simulation study," International Journal of Advanced Manufacturing Technology, vol. 27, pp. 397-406, Dec 2005a.

[39] M. Dong and F. F. Chen, "Performance modeling and analysis of integrated logistic chains: An analytic framework," European Journal of Operational Research, vol. 162, pp. 83-98, Apr 2005b.

[40] P. Fiala, "Information sharing in supply chains," Omega-International Journal of Management Science, vol. 33, pp. 419-423, Oct 2005.

[41] E. Fleisch and C. Tellkamp, "Inventory inaccuracy and supply chain performance: a simulation study of a retail supply chain," International Journal of Production Economics, vol. 95, pp. 373-385, Mar 2005.

[42] M. Fleischmann, et al., "Integrating closed-loop supply chains and spare-parts management at IBM," Interfaces, vol. 33, pp. 44-56, Nov-Dec 2003.

[43] A. Fowler, "Operations management and systemic modelling as frameworks for BPR," International Journal of Operations \& Production Management, vol. 18, pp. 1028-+, 1998.

[44] R. Ganeshan, et al., "The impact of inventory and flow planning parameters on supply chain performance: An exploratory study," International Journal of Production Economics, vol. 71, pp. 111-118, May 2001.

[45] A. C. Garavelli, "Flexibility configurations for the supply chain management," International Journal of Production Economics, vol. 85, pp. 141-153, Aug 2003.

[46] P. Georgiadis and D. Vlachos, "The effect of environmental parameters on product recovery," European Journal of Operational Research, vol. 157, pp. 449-464, Sep 2004.

[47] P. Georgiadis, et al., "A system dynamics modeling framework for the strategic supply chain management of food chains," Journal of Food Engineering, vol. 70, pp. 351-364, Oct 2005.

[48] P. Georgiadis, et al., "The impact of product lifecycle on capacity planning of closedloop supply chains with remanufacturing," Production and Operations Management, vol. 15, pp. 514-527, Win 2006.

[49] I. Giannoccaro and P. Pontrandolfo, "Inventory management in supply chains: a reinforcement learning approach," International Journal of Production Economics, vol. 78, pp. 153-161, Jul 2002.

[50] I. Giannoccaro, et al., "A fuzzy echelon approach for inventory management in supply chains," European Journal of Operational Research, vol. 149, pp. 185-196, Aug 2003.

[51] M. G. Gnoni, et al., "Production planning of a multi-site manufacturing system by hybrid modelling: A case study from the automotive industry," International Journal of Production Economics, vol. 85, pp. 251-262, Aug 2003.

[52] C. Gobel and S. Hocke, "Simulation and analysis of interorganisational business processes," Wirtschaftsinformatik, vol. 43, pp. 589-+, Dec 2001.

[53] S. Goel, et al., "A simulation-based method for the process to allow continuous tracking of quality, cost, and time," Simulation-Transactions of the Society for Modeling and Simulation International, vol. 78, pp. 330-337, May 2002. 
[54] A. Greasley, "Using system dynamics in a discrete-event simulation study of a manufacturing plant," International Journal of Operations \& Production Management, vol. 25, pp. 534-548, 2005.

[55] F. Guerrin, "Simulation of stock control policies in a two-stage production system Application to pig slurry management involving multiple farms," Computers and Electronics in Agriculture, vol. 45, pp. 27-50, Dec 2004.

[56] M. Gupta, et al., "TOC-based performance measures and five focusing steps in a jobshop manufacturing environment," International Journal of Production Research, vol. 40, pp. 907-930, Mar 2002.

[57] K. Hafeez, et al., "Systems design of a two-echelon steel industry supply chain," International Journal of Production Economics, vol. 45, pp. 121-130, Aug 1996.

[58] S. Han, et al., "Comparative study of discrete-event simulation and system dynamics for construction process planning," in ASCE Proceedings of construction research congress: Broadening Perspectives, San Diego, California, USA, 2005.

[59] M. Helal, et al., "A methodology for Integrating and Synchronizing the System Dynamics and Discrete Event Simulation Paradigms," in Proceedings of the 25th International Conference and 50th Anniversary Celebration, July 29 - August 2, 2007, Boston, Massachusetts, USA, 2007.

[60] P. T. Helo, "Dynamic modelling of surge effect and capacity limitation in supply chains," International Journal of Production Research, vol. 38, pp. 4521-4533, Nov 2000.

[61] R. Hieber and I. Hartel, "Impacts of SCM order strategies evaluated by simulationbased 'Beer Game' approach: the model, concept, and initial experiences," Production Planning \& Control, vol. 14, pp. 122-134, Mar 2003.

[62] T. Higuchi and M. D. Troutt, "Dynamic simulation of the supply chain for a short life cycle product - Lessons from the Tamagotchi case," Computers \& Operations Research, vol. 31, pp. 1097-1114, Jun 2004.

[63] M. Holweg and J. Bicheno, "Supply chain simulation - a tool for education, enhancement and endeavour," International Journal of Production Economics, vol. 78, pp. 163-175, Jul 2002.

[64] M. Holweg, et al., "Towards responsive vehicle supply: a simulation-based investigation into automotive scheduling systems," Journal of Operations Management, vol. 23, pp. 507-530, Jul 2005.

[65] W. Y. Hung, et al., "A flexible and generic approach to dynamic modelling of supply chains," Journal of the Operational Research Society, vol. 55, pp. 801-813, Aug 2004.

[66] H. B. Hwarng, et al., "Modelling a complex supply chain: understanding the effect of simplified assumptions," International Journal of Production Research, vol. 43, pp. 2829-2872, Jul 2005.

[67] R. G. Ingalls, "The value of simulation in modelling supply chains," in Proceedings of the 1998 Winter Simulation Conference, 1998, pp. 1371-75.

[68] R. G. Ingalls, et al., "Reducing the bullwhip effect in supply chains with controlbased forecasting," International Journal of Simulation and Process Modelling, vol. 1, pp. 90 -110, 2005.

[69] S. Jain and E. Ervin, "Evaluation of supply chain business process improvement using simulation," International Journal of Simulation and Process Modelling, vol. 1, pp. 138-149, 2005.

[70] D. R. Jansen, et al., "Simulation model of multi-compartment distribution in the catering supply chain," European Journal of Operational Research, vol. 133, pp. 210224, Aug 2001. 
[71] J. G. Jeong, et al., "Supply chain simulation modeling for the manufactured housing industry," Journal of Urban Planning and Development-Asce, vol. 132, pp. 217-225, Dec 2006.

[72] S. Jung, et al., "Vendor managed inventory and its effect in the supply chain," in Systems Modeling and Simulation: Theory and Applications. vol. 3398, ed Berlin: Springer-Verlag Berlin, 2005, pp. 545-552.

[73] N. Karabakal, et al., "Supply-chain analysis at Volkswagen of America," Interfaces, vol. 30, pp. 46-55, Jul-Aug 2000.

[74] S. C. L. Koh and A. Gunasekaran, "A knowledge management approach for managing uncertainty in manufacturing," Industrial Management \& Data Systems, vol. 106, pp. 439-459, 2006.

[75] N. S. Koutsoukis, et al., "A prototype decision support system for strategic planning under uncertainty," International Journal of Physical Distribution and Logistics Management, vol. 30, pp. 640-660, 2000.

[76] E. Kutanoglu and I. Sabuncuoglu, "Experimental investigation of iterative simulationbased scheduling in a dynamic and stochastic job shop," Journal of Manufacturing Systems, vol. 20, pp. 264-279, 2001.

[77] D. C. Lane, "You Just Don't Understand Me: Modes of failure and success in the discourse between system dynamics and discrete event simulation," LSE OR Working Paper 00.34, p. 26, 2000.

[78] E. R. Larsen, et al., "Complex behaviour in production-distribution model," European Journal of Operational Research, vol. 119, pp. 61-74, Nov 1999.

[79] E. R. Larsen, et al., "The growth of service and the service of growth: Using system dynamics to understand service quality and capital allocation," Decision Support Systems, vol. 19, pp. 271-287, 1997.

[80] A. M. Law, Simulation modeling and analysis, 4th ed. Boston; London: McGrawHill, 2007.

[81] Y. H. Lee, et al., "Supply chain simulation with discrete-continuous combined modeling," Computers \& Industrial Engineering, vol. 43, pp. 375-392, Jul 2002.

[82] Y. H. Lee and S. H. Kim, "Production-distribution planning in supply chain considering capacity constraints," Computers \& Industrial Engineering, vol. 43, pp. 169-190, Jul 2002.

[83] S. A. LeMay and W. R. Wood, "Developing Logistics Decision Support Systems," Journal of Business Logistics, vol. 10, pp. 1-23, 1989.

[84] G. Liberopoulos and S. Koukoumialos, "Tradeoffs between base stock levels, numbers of kanbans, and planned supply lead times in production/inventory systems with advance demand information," International Journal of Production Economics, vol. 96, pp. 213-232, 2005.

[85] S. J. Lim, et al., "A simulation approach for production-distribution planning with consideration given to replenishment policies," International Journal of Advanced Manufacturing Technology, vol. 27, pp. 593-603, Jan 2006a.

[86] S. J. Lim, et al., "Hybrid approach to distribution planning reflecting a stochastic supply chain," International Journal of Advanced Manufacturing Technology, vol. 28, pp. 618-625, Mar 2006b.

[87] G. Lin, et al., "Extended-enterprise supply-chain management at IBM personal systems group and other divisions," Interfaces, vol. 30, pp. 7-25, Jan-Feb 2000.

[88] G. Lo Nigro, et al., "Coordination policies to support decision making in distributed production planning," Robotics and Computer-Integrated Manufacturing, vol. 19, pp. 521-531, Dec 2003. 
[89] T. P. Lu, et al., "Production control framework for supply chain management - an application in the elevator manufacturing industry," International Journal of Production Research, vol. 43, pp. 4219-4233, Oct 2005.

[90] J. A. D. Machuca and R. P. Barajas, "The impact of electronic data interchange on reducing bullwhip effect and supply chain inventory costs," Transportation Research Part E-Logistics and Transportation Review, vol. 40, pp. 209-228, May 2004.

[91] A. C. Marquez, et al., "Operational and financial effectiveness of e-collaboration tools in supply chain integration," European Journal of Operational Research, vol. 159, pp. 348-363, Dec 2004.

[92] A. C. Marquez and C. Blanchar, "The procurement of strategic parts. Analysis of a portfolio of contracts with suppliers using a system dynamics simulation model," International Journal of Production Economics, vol. 88, pp. 29-49, Mar 2004.

[93] R. Mason-Jones and D. R. Towill, "Total cycle time compression and the agile supply chain," International Journal of Production Economics, vol. 62, pp. 61-73, May 1999.

[94] S. J. Mason, et al., "Integrating the warehousing and transportation functions of the supply chain," Transportation Research Part E-Logistics and Transportation Review, vol. 39, pp. 141-159, Mar 2003.

[95] K. Mertins, et al., "Distributed modelling and simulation of supply chains," International Journal of Computer Integrated Manufacturing, vol. 18, pp. 342-349, Jul-Aug 2005.

[96] R. Metz, et al., "A supply chain management system in a pharmaceutical company," Pharmazeutische Industrie, vol. 66, pp. 1436-1441, 2004.

[97] S. Minegishi and D. Thiel, "System dynamics modeling and simulation of a particular food supply chain," Simulation Practice and Theory, vol. 8, pp. 321-339, Dec 2000.

[98] S. A. Moon and D. J. Kim, "Systems thinking ability for supply chain management," Supply Chain Management-an International Journal, vol. 10, pp. 394-401, 2005.

[99] J. D. W. Morecroft and S. Robinson, "Explaining Puzzling Dynamics: Comparing the Use of System Dynamics and Discrete-Event Simulation," in In Proceedings of the 23rd International Conference of the System Dynamics Society, Boston, 2005.

[100] J. Mula, et al., "Models for production planning under uncertainty: A review," International Journal of Production Economics, vol. 103, pp. 271-285, 2006.

[101] J. Myers and E. W. Richards, "Supporting wood supply chain decisions with simulation for a mill in northwestern BC," Infor, vol. 41, pp. 213-234, Aug 2003.

[102] M. M. Naim, "The impact of the net present value on the assessment of the dynamic performance of e-commerce enabled supply chains," International Journal of Production Economics, vol. 104, pp. 382-393, Dec 2006.

[103] P. R. Nair and O. A. Balasubramaniam. (2010) IT-Enabled Supply Chain Management using Decision Support Systems. CSI Communications. 34-40.

[104] R. Narasimhan and S. Mahapatra, "Decision models in global supply chain management," Industrial Marketing Management, vol. 33, pp. 21-27, Jan 2004.

[105] J. Olhager and F. Persson, "Simulating production and inventory control systems: a learning approach to operational excellence," Production Planning \& Control, vol. 17, pp. 113-127, Mar 2006.

[106] A. Otto and H. Kotzab, "Does supply chain management really pay? Six perspectives to measure the performance of managing a supply chain," European Journal of Operational Research, vol. 144, pp. 306-320, 2003.

[107] O. R. Ovalle and A. C. Marquez, "Exploring the utilization of a CONWIP system for supply chain management. A comparison with fully integrated supply chains," International Journal of Production Economics, vol. 83, pp. 195-215, Feb 2003. 
[108] A. Oyarbide, et al., "Manufacturing systems modelling using system dynamics: forming a dedicated modelling tool," Journal of advances manufacturing systems, vol. 2, pp. 71-87, 2003.

[109] M. Ozbayrak, et al., "A flexible and adaptable planning and control system for an MTO supply chain system," Robotics and Computer-Integrated Manufacturing, vol. 22, pp. 557-565, Oct-Dec 2006.

[110] F. Persson and J. Olhager, "Performance simulation of supply chain designs," International Journal of Production Economics, vol. 77, pp. 231-245, 2002.

[111] D. Petrovic, "Simulation of supply chain behaviour and performance in an uncertain environment," International Journal of Production Economics, vol. 71, pp. 429-438, May 2001.

[112] D. Petrovic, et al., "Supply chain modelling using fuzzy sets," International Journal of Production Economics, vol. 59, pp. 443-453, Mar 1999.

[113] D. Petrovic, et al., "Modelling and simulation of a supply chain in an uncertain environment," European Journal of Operational Research, vol. 109, pp. 299-309, Sep 1998.

[114] M. Pidd, Computer Simulation in Management Science, 5th edition ed. Chichester: John Wiley \& Sons, 2004.

[115] M. Quaddus and A. Intrapairot, "Management policies and the diffusion of data warehouse: a case study using system dynamics-based decision support system," Decision Support Systems, vol. 31, pp. 223-240, 2001.

[116] L. Rabelo, et al., "Enterprise simulation: a hybrid system approach," International Journal of Computer Integrated Manufacturing, vol. 18, pp. 498-508, 2005.

[117] S. Rafaeli and G. Ravid, "Information sharing as enabler for the virtual team: an experimental approach to assessing the role of electronic mail in disintermediation," Information Systems Journal, vol. 13, pp. 191-206, Apr 2003.

[118] J. J. Rao, et al., "A simulation-based approach to study stochastic inventory-planning games," International Journal of Systems Science, vol. 34, pp. 717-730, Oct 2003.

[119] A. Rathore, et al., "Development and benchmarking of an epoch time synchronization method for distributed simulation," Journal of Manufacturing Systems, vol. 24, pp. 69-78, 2005.

[120] K. K. Ravulapati, et al., "A reinforcement learning approach to stochastic business games," Iie Transactions, vol. 36, pp. 373-385, Apr 2004.

[121] G. Reiner, "Customer-oriented improvement and evaluation of supply chain processes supported by simulation models," International Journal of Production Economics, vol. 96, pp. 381-395, Jun 2005.

[122] G. Reiner and M. Trcka, "Customized supply chain design: Problems and alternatives for a production company in the food industry. A simulation based analysis," International Journal of Production Economics, vol. 89, pp. 217-229, May 2004.

[123] G. P. Richardson, Feedback thought in social science and systems theory. Philadelphia. PA: University of Pennsylvania Press, 1991.

[124] P. Rios, et al., "Plastics disassembly versus bulk recycling: Engineering design for end-of-life electronics resource recovery," Environmental Science \& Technology, vol. 37, pp. 5463-5470, Dec 2003.

[125] P. J. Rios and J. A. Stuart, "Scheduling selective disassembly for plastics recovery in an electronics recycling center," Ieee Transactions on Electronics Packaging Manufacturing, vol. 27, pp. 187-197, Jul 2004.

[126] S. Robinson, Simulation: The Practice of Model Development and Use. Chichester: John Wiley \& Sons, 2004. 
[127] N. Saad and V. Kadirkamanathan, "A DES approach for the contextual load modelling of supply chain system for instability analysis," Simulation Modelling Practice and Theory, vol. 14, pp. 541-563, Jul 2006.

[128] M. Schwaninger and P. Vrhovec, "Supply system dynamics: Distributed control in supply chains and networks," Cybernetics and Systems, vol. 37, pp. 375-415, Jul-Aug 2006.

[129] N. Shah, "Process industry supply chains: Advances and challenges," Computers \& Chemical Engineering, vol. 29, pp. 1225-1235, May 2005.

[130] J. S. Shang, et al., "Operational design of a supply chain system using the Taguchi method, response surface methodology, simulation, and optimization," International Journal of Production Research, vol. 42, pp. 3823-3849, Sep 2004.

[131] H. J. Shin and W. C. Benton, "Quantity discount-based inventory coordination: Effectiveness and critical environmental factors," Production and Operations Management, vol. 13, pp. 63-76, Spr 2004.

[132] D. Simchi-Levi, et al., Designing and Managing the Supply Chain, 3rd ed. ed. New York, London: McGraw-Hill Education, 2007.

[133] D. Sirias and S. Mehra, "Quantity discount versus lead time-dependent discount in an inter-organizational supply chain," International Journal of Production Research, vol. 43, pp. 3481-3496, Aug 2005.

[134] S. Sokhansanj, et al., "Development and implementation of integrated biomass supply analysis and logistics model (IBSAL)," Biomass \& Bioenergy, vol. 30, pp. 838-847, Oct 2006.

[135] T. Spengler and M. Schroter, "Strategic management of spare parts in closed-loop supply chains - A system dynamics approach," Interfaces, vol. 33, pp. 7-17, Nov-Dec 2003.

[136] J. D. Sterman, Business Dynamics: Systems Thinking and Modeling for a Complex World. London: McGraw-Hill, 2000.

[137] P. Suwanruji and S. T. Enns, "Evaluating the effects of capacity constraints and demand patterns on supply chain replenishment strategies," International Journal of Production Research, vol. 44, pp. 4607-4629, Nov 2006.

[138] J. M. Swaminathan, et al., "Modeling supply chain dynamics: A multiagent approach," Decision Sciences, vol. 29, pp. 607-632, Sum 1998.

[139] A. Sweetser, "A Comparison of System Dynamics and Discrete Event Simulation," in In Proceedings of 17th International Conference of the System Dynamics Society and 5th Australian \& New Zealand Systems Conference, Wellington, New Zealand, 1999.

[140] A. A. Tako and S. Robinson, "Comparing discrete-event simulation and system dynamics: Users’ perceptions," Journal of the Operational Research Society, vol. 60, pp. 296-312, 2009.

[141] A. A. Tako and S. Robinson, "Model development in discrete-event simulation and system dynamics: an empirical view," European Journal of Operational Research, vol. 207, pp. 784-794, 2010.

[142] O. Tang and M. M. Naim, "The impact of information transparency on the dynamic behaviour of a hybrid manufacturing/remanufacturing system," International Journal of Production Research, vol. 42, pp. 4135-4152, Oct 2004.

[143] K. Taylor and D. Lane, "Simulation applied to health services: opportunities for applying the system dynamics approach," Journal of health services research and policy, vol. 3, pp. 226-232, 1998.

[144] I. D. Tommelein, "Pull-driven scheduling for pipe-spool installation: Simulation of lean construction technique," Journal of Construction Engineering and ManagementAsce, vol. 124, pp. 279-288, Jul-Aug 1998. 
[145] D. R. Towill, "Industrial dynamics modelling of supply chains," Logistics Information Management, vol. 9, pp. 43-56, 1996.

[146] S. Umeda and F. Zhang, "Supply chain simulation: generic models and application examples," Production Planning \& Control, vol. 17, pp. 155-166, Mar 2006.

[147] M. Vamanan, et al., "Integration of COTS software products ARENA \& CPLEX for an inventory/logistics problem," Computers \& Operations Research, vol. 31, pp. 533547, Apr 2004.

[148] J. van der Vorst, et al., "Modelling and simulating multi-echelon food systems," European Journal of Operational Research, vol. 122, pp. 354-366, Apr 2000.

[149] D.-J. van der Zee, "Building insightful simulation models using Petri Nets - A structured approach," Decision Support Systems, vol. 51, pp. 53-64, 2011.

[150] D. J. van der Zee and J. van der Vorst, "A modeling framework for supply chain simulation: Opportunities for improved decision making," Decision Sciences, vol. 36, pp. 65-95, Feb 2005.

[151] J. Venkateswaran and Y. J. Son, "Design and development of a prototype distributed simulation for evaluation of supply chains," International Journal of Industrial Engineering-Theory Applications and Practice, vol. 11, pp. 151-160, Jun 2004.

[152] J. Venkateswaran and Y. J. Son, "Hybrid system dynamic-discrete event simulationbased architecture for hierarchical production planning," International Journal of Production Research, vol. 43, pp. 4397-4429, Oct 2005.

[153] F. A. Villegas and N. R. Smith, "Supply chain dynamics: analysis of inventory vs. order oscillations trade-off," International Journal of Production Research, vol. 44, pp. 1037-1054, Mar 2006.

[154] K. D. Walsh, et al., "Strategic positioning of inventory to match demand in a capital projects supply chain," Journal of Construction Engineering and Management-Asce, vol. 130, pp. 818-826, Nov-Dec 2004.

[155] K. Watson and T. Polito, "Comparison of DRP and TOC financial performance within a multi-product, multi-echelon physical distribution environment," International Journal of Production Research, vol. 41, pp. 741-765, 2003.

[156] K. O. Willis and D. F. Jones, "Multi-objective simulation optimization through search heuristics and relational database analysis," Decision Support Systems, vol. 46, pp. 277-286, 2008.

[157] J. H. Xu and K. L. Hancock, "Enterprise-wide freight simulation in an integrated logistics and transportation system," Ieee Transactions on Intelligent Transportation Systems, vol. 5, pp. 342-346, Dec 2004.

[158] S. T. Yee, "Impact analysis of customized demand information sharing on supply chain performance," International Journal of Production Research, vol. 43, pp. 33533373, Aug 2005.

[159] Z. Z. Ying and R. De Souza, "Intelligent control of an internal supply chain in the hard disk drive industry," Journal of Electronics Manufacturing, vol. 8, pp. 103-116, Jun 1998.

[160] S. Zanoni, et al., "Cost performance and bullwhip effect in a hybrid manufacturing and remanufacturing system with different control policies," International Journal of Production Research, vol. 44, pp. 3847-3862, Sep 2006.

[161] C. Zhang, et al., "Sharing shipment quantity information in the supply chain," Omega-International Journal of Management Science, vol. 34, pp. 427-438, Oct 2006.

[162] X. D. Zhao and J. X. Xie, "Forecasting errors and the value of information sharing in a supply chain," International Journal of Production Research, vol. 40, pp. 311-335, Jan 2002. 
[163] X. D. Zhao, et al., "Improving the supply chain performance: use of forecasting models versus early order commitments," International Journal of Production Research, vol. 39, pp. 3923-3939, Nov 2001.

[164] X. D. Zhao, et al., "The impact of forecast errors on early order commitment in a supply chain," Decision Sciences, vol. 33, pp. 251-280, Spr 2002. 